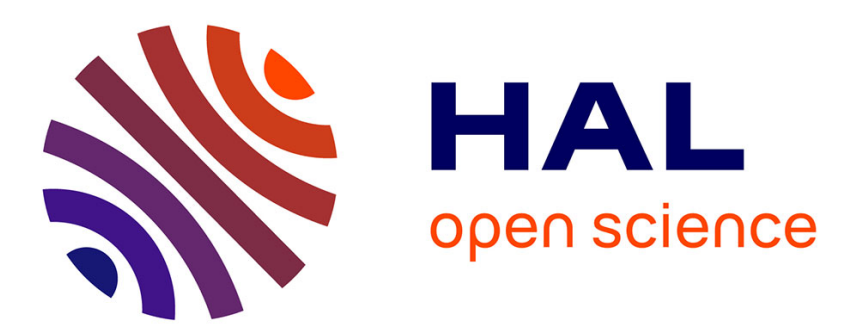

\title{
Comparative investigation of the Ti and Mo additives influence on the opto-electronic properties of the spray deposited WO3 thin films
}

Laura Maria Manceriu, Aline Rougier, Anca Duta

\section{- To cite this version:}

Laura Maria Manceriu, Aline Rougier, Anca Duta. Comparative investigation of the Ti and Mo additives influence on the opto-electronic properties of the spray deposited WO3 thin films. Journal of Alloys and Compounds, 2015, 630, pp.133-145. 10.1016/j.jallcom.2014.12.240 . hal-01112273

\section{HAL Id: hal-01112273 \\ https://hal.science/hal-01112273}

Submitted on 9 Feb 2021

HAL is a multi-disciplinary open access archive for the deposit and dissemination of scientific research documents, whether they are published or not. The documents may come from teaching and research institutions in France or abroad, or from public or private research centers.
L'archive ouverte pluridisciplinaire HAL, est destinée au dépôt et à la diffusion de documents scientifiques de niveau recherche, publiés ou non, émanant des établissements d'enseignement et de recherche français ou étrangers, des laboratoires publics ou privés. 
Comparative investigation of the $\mathrm{Ti}$ and Mo additives influence on the opto-electronic properties of the spray deposited $\mathrm{WO}_{3}$ thin films

\author{
Laura Maria MANCERIU ${ }^{\mathrm{a}, b^{*}}$, Aline ROUGIER ${ }^{\mathrm{a}}$, Anca DUTA ${ }^{\mathrm{b} * *}$ \\ ${ }^{a}$ Current address: CNRS, Université de Bordeaux, ICMCB, 87 Avenue du Dr. Albert Schweitzer, \\ F-33608 Pessac, France \\ ${ }^{b}$ The RTD Dept. Renewable Energy Systems and Recycling, University of Transilvania Brasov, \\ Eroilor 29, 500036 Brasov, Romania \\ *Corresponding author: L.M. Manceriu.manceriu.laura@gmail.com \\ **Corresponding author: A. Duta, a.duta@unitbv.ro
}

\begin{abstract}
In this paper we compare the optical and electrical properties of the $\mathrm{WO}_{3}$ thin films containing 2, 5 and 10 at $\%$ of $\mathrm{Ti}$ and Mo additives deposited by spray pyrolysis. The influence of the type and additive concentration on the nanostructure, topography and composition of the $\mathrm{WO}_{3}$ layers are mainly related to the surface tension energy changes, and further correlated with the (photo)electrical and optical properties. The $\mathrm{FTO} / \mathrm{WO}_{3}$ junction through its characteristic, namely barrier height, ideality factor, flat band potential, and series resistance, served as a tool for associating the before mentioned characteristics.

The morphology of the $\mathrm{WO}_{3}$ thin films densifies and the roughness is reduced with increasing $\mathrm{Ti}$ and Mo concentration, in good agreement with solution surface tension reduction. $\mathrm{WO}_{3}$ based films exhibit a p-type semiconducting behavior, as confirmed also by the Mott-Schottky analysis, with a lower ptype conductivity for the $\mathrm{Ti}-\mathrm{WO}_{3}$ films, as higher number of oxygen vacancies are generated by $\mathrm{Ti}$ addition. Changes in conductivity are mainly attributed to the oxygen vacancies concentration evolution at the film surface due oxygen/water adsorption. For heavily doped $\mathrm{WO}_{3}$ thin films the contribution of these surface processes to the overall conductivity is reduced since surface reactivity is lost by densification.

As opposed to Ti-doping which has a detrimental effect on layers structure, Mo addition, even in high concentrations, has a positive effect on layers crystallinity; hence higher conductivity and ideality factors close to 1 are obtained for these films. Surprisingly, Ti and $\mathrm{Mo}-\mathrm{WO}_{3}$ films contain cation additives also in lower oxidation states, $3+$ and 5+, respectively, compared to the ones in the precursor salt. A $2 \%$ at. Ti concentration is enough to significantly improve the photoconductivity of the $\mathrm{WO}_{3}$ films, whereas for Mo addition higher levels are needed (10\% at.). The Ti and $\mathrm{Mo}-\mathrm{WO}_{3}$ films have high transparency with average transmission values of $85 \%$ and $75 \%$, respectively. The thin films reflectance decreases with increasing doping concentration along with roughness diminution.
\end{abstract}

Keywords: $\mathrm{WO}_{3}$, spray pyrolysis, doping, solution surface tension, Fermi level, opto-electronic properties. 


\section{Introduction}

Tungsten oxide is a versatile material involved in a wide variety of devices, such as gas sensors [1] or electrochromic devices [2], and processes as water splitting [3], and photocatalytic degradation [4]. Band gap tailoring at the ultraviolet and toward the visible region of the solar spectrum is of considerable interest for applications relying on harvesting the solar radiation such as photocatalysis and solar cells. Metal ion doping has frequently been applied to extend the $\mathrm{WO}_{3}$ photo-response in the visible region. $\mathrm{WO}_{3}$ doped with $\mathrm{Ta}^{5+}[5], \mathrm{Mg}^{2+}, \mathrm{Al}^{3+}, \mathrm{In}^{3+}, \mathrm{Fe}^{3+}, \mathrm{Zr}^{4+}$ [6] showed much better photophysical properties than pristine $\mathrm{WO}_{3}$. Doping $\mathrm{WO}_{3}$ powders with $\mathrm{Ti}^{3+}, \mathrm{V}^{4+}, \mathrm{Cr}^{3+}, \mathrm{Mn}^{2+}, \mathrm{Fe}^{3+}, \mathrm{Co}^{2+}$, $\mathrm{Ni}^{2+}, \mathrm{Zn}^{2+}$ and $\mathrm{Cu}^{2+}$ increased the absorbance in the visible region of the solar radiation [3,7]. Radecka et. al. [8] also found an improvement in the photo-electrochemical properties of Ti-doped $\mathrm{WO}_{3}$ with respect to the un-doped one.

Tungsten oxide is the most common inorganic material used in electrochromic applications. $\mathrm{WO}_{3}$ easily and reversibly modulates transmission in the visible and near infrared region of the spectra with a small potential activation. Metal ion doping of $\mathrm{WO}_{3}$ was also applied for enhancing chemical stability and coloration efficiency of the layers and eventually extending their cycling life. Amounts of $1 \%$ and $5 \%$ of $\mathrm{Sn}^{4+}$ and $\mathrm{Mo}^{6+}$ additives were shown to improve the electrochromic behavior of the $\mathrm{WO}_{3}$ layers obtained by sol-gel [9] along with increasing crystalline disorder. The cycle stability, charge capacity and reversibility of the $\mathrm{WO}_{3}$ films were improved upon doping with $\mathrm{Nb}^{5+}$ because of increasing porosity; however, coloration efficiency decreased [10]. Patil et al. [11] also reported enhanced properties for electrochromic $9 \%$ at. $\mathrm{Ti}^{-\mathrm{WO}_{3}}$ synthesized by spray pyrolysis. J-M O-Rueda de Leon et al. [12] demonstrated that coloration efficiency, reversibility and stability of $\mathrm{WO}_{3}$ thin films can be improved by 2-6 at.\% Mo doping and concludes that the amount of Mo in the starting solution affects the grain growth and that exceeding the optimum doping level leads to layer densification. Cations like $\mathrm{V}^{5+}$ [13], $\mathrm{Nb}^{5+}$ [14] or $\mathrm{Mo}^{6+}$ [15] doping of $\mathrm{WO}_{3}$ have also been used in order to achieve color neutrality. Hence, doping also induces modifications in layer morphology.

$\mathrm{WO}_{3}$ thin films can be synthesized by processes involving physical transformation, here including sputtering [16-18] and evaporation [19,20], or by techniques based on chemical processes occurring either in the gas phase, such as chemical vapor deposition (CVD) [21,22], or in solution including electrodeposition [23,24], anodization [25], sol-gel deposition [26,27] and spray pyrolysis. Wet chemical routes offer good reproducibility and control in terms of crystallinity, thickness and porosity by making use of less expensive technology, adaptable for different kinds of substrates and precursors. 
Among them, spray pyrolysis deposition (SPD) is a cost efficient technique that does not require complicated equipment, and can be easily transferred to large scale industry fabrication processes. A schema of the spray pyrolysis deposition process including all the parameters that should be taken into account for obtaining good quality films is presented in Fig. 1, together with the deriving factors which influence the layer growth.

Fig. 1. Comprehensive illustration of the spray pyrolysis process (SPD), showing the variable deposition parameters and their inter-dependency.

One sequence of SPD consists of the following steps: (1) the formation of an aerosol Taylor cone by atomization of the precursor solution; (2) the transport of the aerosol to the heated substrate using a carrier gas with a controlled pressure (the evaporation of the solvent within the droplet occurs during this stage); (3) adsorption and chemical reaction of the precursor on the substrate; (4) by-products removal. Ideally the solvent evaporates completely close to the substrate where the reactant molecules undergo chemical reactions which lead to nucleation and layer growth. The nucleation process is under kinetic control and is characterized by the nucleation rate, $v_{n}=k(c-s) / s$ (where: $\mathrm{k}$ is the rate constant, $k=k_{0} e^{-E_{a} / R T}, \mathrm{c}$ is the concentration of the precursor [mol/L], $\mathrm{s}$ is the solubility of the resulting oxide $[\mathrm{mol} / \mathrm{L}], \mathrm{k}_{0}$ is the pre-exponential factor, $\mathrm{R}$ is the gas constant $[\mathrm{J} / \mathrm{molK}], T$ is the temperature $[\mathrm{K}], \mathrm{E}_{\mathrm{a}}$ is the activation energy $[\mathrm{J} / \mathrm{mol}]$ ) [28]. In conclusion, nucleation can be mainly controlled by modifying the precursor solution concentration, for a given temperature. The growth process depends on the diffusion coefficient (D) of the species on the substrate, $v_{g}=S D(c-s) / x$ (where $\mathrm{s}$ is the surface of the nucleation germs $\left[\mathrm{m}^{2}\right]$ and $(\mathrm{c}-\mathrm{s}) / \mathrm{x}$ is the concentration gradient $[\mathrm{mol} / \mathrm{L}])$.

Spraying perpendicularly to the substrate may lead to solution dropping and for this reason but also for encouraging diffusion on the surface a $45^{\circ}$ spraying angle is preferred.

The growth rate is mainly influenced by the deposition temperature but also by solution viscosity, [29], through the diffusion coefficient D:

$$
D=R T / 6 \pi r_{s} \eta N_{A}
$$

where $r_{\mathrm{s}}$ is the droplet radius $[\mathrm{m}], \eta$ is the viscosity $[\mathrm{kg} / \mathrm{ms}]$ and $\mathrm{N}_{\mathrm{A}}$ is the Avogadro number $\left[\mathrm{mol}^{-1}\right.$ ]. 
For $\mathrm{v}_{\mathrm{n}}>\mathrm{v}_{\mathrm{g}}$ dense and uniform films are formed as a large number of nucleation centers are formed, characterized by slow growth, whereas for $v_{n}<v_{g}$ the nucleation centers are smaller in number but characterized by fast growth resulting in large aggregates which lead to films with increased roughness. Layer homogeneity and thickness can be controlled by modifying the number of spraying sequences and their surface geometry. The break time between the spraying sequences must be long enough to allow removing the solvent and the growth controlling agents which are usually organic, and also to support the substrate reheating to the initial deposition temperature before a new layer is deposited, but short enough to avoid unwanted in situ annealing. In most cases, annealing is finally applied for the removal of solvent, by-products or templating agents and for stabilizing the films crystalline structure. Depending on the duration, temperature and annealing atmosphere, crystallinity, stoichiometry and morphology can be tuned.

An important advantage of SPD is that it allows using, both inorganic (nitrates, chlorides) and organometallic (acetates or ethoxydes) precursors, [30]. $\mathrm{WO}_{3}$ thin films were prepared by SPD starting from different precursor solutions including aqueous solutions of ammonium tungstate $\left(\left(\mathrm{NH}_{4}\right)_{2} \mathrm{WO}_{4}\right)[31,32]$ and peroxotungstate [33], $\mathrm{WCl}_{6}$ dissolved in $\mathrm{N}-\mathrm{N}$ dimethylformamide [34] or in a mixture of ethanol:water (50:50 \%) [35] and also $\mathrm{W}\left(\mathrm{OC}_{2} \mathrm{H}_{5}\right)_{6}$ ethanolic solution [36]. By modifying the precursor solution composition (concentration, type of precursor, addition of doping or growth controlling agents, using different/mixed solvents) we inevitably change its physical properties (viscosity, surface tension and vapor pressure) with further consequences on the film formation processes [37]. The aerosol flow rate $\left(F_{a}\right)$ is influenced by the liquid properties, such as vapor pressure $(P)$, viscosity $(\eta)$ and surface tension $(\sigma),[38]$ :

$$
F_{a}=K \sqrt{\frac{P}{\eta \sigma}}, \mathrm{K}-\text { coefficient depending on the power needed to generate the aerosol }
$$

The radius of the droplets ( $\mathrm{r}_{\mathrm{S}}$ ) depends on the properties of the precursor (molar mass) and precursor solution (surface tension, density and vapor pressure) but also on the deposition temperature and carrier gas pressure, as shown by the Kelvin equation[39]:

$$
r_{s}=\frac{2 M \gamma}{R T \rho \ln \frac{p}{p_{0}}}
$$

where $\mathrm{p}$ is the vapor pressure inside the droplet and $\mathrm{p}_{0}$ is the vapor pressure outside $\left(\mathrm{N} / \mathrm{m}^{2}\right), \gamma$ is the surface tension $(\mathrm{N} / \mathrm{m}), M$ is precursor molar mass $(\mathrm{g} / \mathrm{mol}), \rho$ is the precursor density $\left(\mathrm{g} / \mathrm{cm}^{3}\right)$ and $\mathrm{R}$ and $\mathrm{T}$ were previously defined. With increasing deposition temperature solvent evaporation rate within the 
droplets increases, resulting in smaller droplets rich in precursor, with higher nucleation rate. At too high temperature the solvent evaporates before reaching the substrates and dry precipitates hit the substrate, leading to poor quality films. On the other hand, according to Viguie and Spitz [40] at low deposition temperatures the droplets splash on the substrate as the solvent is not completely evaporated, causing a randomly/localized distribution of temperature over the substrate, uneven distribution of nucleation centers and preferential landing of the new incoming reactive species. The result is powdery films with high roughness and most probably with cracks because of uneven solvent evaporation. Carrier gas pressure has direct consequences on the spraying cone homogeneity and droplet size and speed. At low pressure, the particles adopt a random direction and do not have enough kinetic energy to reach the substrate; with increasing pressure the droplet size decreases and for too high carrier gas pressure, the substrate is "washed out" and the temperature drops significantly leading to poor quality films.

In this paper we present a comparative study on the effect of $\mathrm{Ti}$ and Mo (2, 5 and 10 at. \%) addition on the opto-electronic properties of $\mathrm{WO}_{3}$ layers deposited by SPD. This study allows outlining that the changes in crystallinity structure, morphology and composition, with further impact on the optoelectronic properties of the $\mathrm{WO}_{3}$ layer, should be first and foremost correlated with the modification of the spraying solution surface tension. These correlations are not always obvious and were not evidenced in previous studies reporting the properties of doped inorganic thin films obtained by SPD although they are meaningful for technological transfer.

This study also proves that the analysis of the $\mathrm{FTO} / \mathrm{WO}_{3}$ junction is a valuable tool in diagnosing the layer reproducibility and quality, as good conductivity is obtained for highly ordered materials. The barrier height, ideality factor and series resistance parameters were extracted from the current - voltage (I-V) curves, and the carrier concentration and flat band potential were extracted from the Mott-Schottky analysis of the same junction, and correlated with the crystalline structure, morphology and composition of the $\mathrm{WO}_{3}$ based thin films, properties which are intimately related to the spraying solution surface tension modification. Moreover, it is shown that the postdeposition conditions, here meaning films reactivity with surrounding atmosphere during heating and cooling, influences the semiconducting behavior.

\section{Experimental details}

\subsection{Thin films deposition}


Tungsten oxide $\left(\mathrm{WO}_{3}\right)$ thin layers were deposited on electrical conductive fluorine-doped tin oxide substrates (FTO, Pilkington, sheet resistance $30 \Omega / \mathrm{sq}$ ) using spray pyrolysis. Before deposition, cleaning of the $2.5 \mathrm{~cm} \times 2.5 \mathrm{~cm}$ FTO substrates was done by degreasing with $\mathrm{pH}$ neutral detergent, rinsing with deionized water and ultra-sonication in ethanol, followed by drying under compressed air flow. During deposition, the substrate temperature $\left(250{ }^{\circ} \mathrm{C}\right)$, air flow pressure $(150 \mathrm{kPa})$, spraying angle $\left(45^{\circ} \mathrm{C}\right)$ and spraying distance $(23 \mathrm{~cm})$ were kept constant. For obtaining the aerosols a glass atomizer (Camag, $100 \mathrm{~mL}$ ) was used. Fifteen consecutive layers were deposited with 100s break between sequences as previously optimized [37].

The precursor solutions were obtained by dissolving $\mathrm{WCl}_{6}$ powder (99.9+ \%, Acrős Organics) in alcohol $\left(\mathrm{C}_{2} \mathrm{H}_{5} \mathrm{OH}, 99.2 \%\right.$, P.A.M. Corporation S.R.L) and addition of acetylacetone (AcAc, $99 \%$, Alfa Aesar), with $\mathrm{WCl}_{6}$ and AcAc in a 1:2 molar ratio.

Proper amounts of additive precursors, here including $\mathrm{TiCl}_{4}$ (anhydrous, $99.99 \%$, Alfa Aesar) and $\mathrm{MoCl}_{6}$ (anhydrous, $95 \%$, Acrős Organics) inorganic salts, were added to the spraying solution in order to reach 2, 5 and 10 at.\% levels. The samples were named as follows: $\mathrm{W}-$ the $\mathrm{WO}_{3}$ layer, WT2, WT5 and WT10, and WM2, WM5 and WM10 for the 2, 5 and 10 at. \% Ti(Mo) films, respectively. The films were annealed in air for six hours, at $410{ }^{\circ} \mathrm{C}$ for stabilizing the crystalline structure and rapidly cooled down to room temperature.

\subsection{Thin films characterization}

Before deposition, the surface tension energy of all the solutions was measured by the stalagmometric method (measurement accuracy $\pm 0.02 \mathrm{mN} / \mathrm{m}$ ). The surface morphology of the (un)doped $\mathrm{WO}_{3}$ films was firstly inspected by Scanning Electron Microscopy (SEM with a Philips XL 30 field emission gun). Additionally, the effect of cation doping on the surface morphology (roughness, porosity) and crystalline structure were investigated using atomic force microscopy (NT-MDT model NTGRA PRIMA EC, semi-contact mode with Si-tips, NSG10, force constant $0.15 \mathrm{~N} / \mathrm{m}$, tip radius $10 \mathrm{~nm}$ ) and X-ray diffraction (Advanced D8 Discover Bruker diffractometer, $\mathrm{K}_{\alpha 1}=1.5406 \AA$, $40 \mathrm{~kW}, 20 \mathrm{~mA}$, step size 0.02 , scan speed 2 sec/step, $2 \theta$ range from 20 to $60^{\circ}$ ). Surface composition and cationic distribution of the $\mathrm{WO}_{3}$ based thin films were investigated by X-ray photoelectron spectroscopy (VG 220i-XL ESCALAB spectrometer, monochromatic Al Ka excitation, $1486.6 \mathrm{eV}$, accuracy $\pm 0.1 \mathrm{eV}$ ). Transmittance and total reflectance spectra (Perkin Elmer Lambda 25 UV-VIS spectrometer) of the $\mathrm{WO}_{3}$ thin films were measured with report to the FTO substrate in the $300-1100 \mathrm{~nm}$ range. 
The layer thickness was calculated from the transmission spectra in the weak and medium absorbing region, by using the envelope method elaborated by Swanepoel [41].

$$
t=\frac{\lambda_{1} \lambda_{2}}{2\left(\lambda_{1} n_{2}-\lambda_{2} n_{1}\right)}
$$

Where: $\mathrm{n}_{1}$ and $\mathrm{n}_{2}$ are the refractive indices of two adjacent maxima which correspond to the wavelengths $\lambda_{1}$ and $\lambda_{2}$. The films thicknesses are further gathered in Table 1.

The semiconducting behavior of the thin films was investigated by current-voltage measurements (Princeton Applied Research VSP potentiostat, model HM 8143, with frequency analyzer) using the two-point probe method and gold tips as contacts displaced at constant distance (on the FTO and on the film); the voltage was varied in the $\pm 2.0 \mathrm{~V}$ range with a $30 \mathrm{mV} / \mathrm{s}$ scan speed. Using the same setup, the Mott-Schottky analysis (frequency range $1 \mathrm{kHz}-1 \mathrm{MHz}$, bias range from 0 to $3.0 \mathrm{~V}$ ) was used to evaluate the carrier density and the flat band potential. Photocurrent measurements were performed under constant applied bias of $0.01 \mathrm{~V}$ (without biasing there is no photocurrent generation) with thin films illuminated from the FTO side using an Oriel model $7123 \mathrm{UV}$-VIS light source coupled to a monochromator (Acton, SpectraPro 2150i) limited to the $390 \mathrm{~nm}$ wavelength (17 $\left.\mathrm{mWcm}^{-2}\right)$, corresponding to the wavelength for which the maximum photo-response was obtained.

\section{Results and discussions}

\subsection{Surface tension}

As previously mentioned, the type and amount of inorganic salt added to the spraying solution influences the solvent evaporation rate within the aerosol droplets and the droplets speed through the modification of the surface tension. The surface tension energy values for all the spraying solutions are presented in Fig. 2. The surface tension values of the precursor solutions decrease with increasing additive level, with lower values for the Mo containing solutions. This effect was previously reported for mixed water-organic systems to which different inorganic salts were added [42-44]. For the precursor solution without added foreign cations the $\mathrm{W}^{6+}$ cation is stabilized by forming a complex with acetylacetone (AcAc) and the $\mathrm{Cl}^{-}$anions are distributed around it (Fig. 3a). The second solvation shell is formed by the ethanol molecules hydrogen-bonded to the ethanol molecules which are attached to the $\mathrm{Cl}^{-}$anions. 
Fig. 2. Surface tension energy values of the spraying solutions with and without additive cation precursors.

Fig. 3 Illustration of the $\mathrm{W}^{6+-}$ AcAc complex solvation in the solution without (a) and in the presence (b) of additives, in the ethanol media.

The doping cation charge density determines its capability to break the second solvation shell or rather remain close to the air/solvent interface. A decreasing surface tension, as evidenced in this study, implies that ions accumulate at the ethanol/air interface, also known as the Jones-Ray effect [45]. The $\mathrm{Mo}^{6+}$ cation has a lower charge density than $\mathrm{Ti}^{4+}$ because its higher ionic radius $(0.59 \AA$ for octahedralcoordinated $\mathrm{Mo}^{6+}$ and $0.42 \AA$ for tetrahedral-coordinated $\mathrm{Ti}^{4+}$, [46]) and higher charge, and consequently forms weaker H-bonds with ethanol (ethanol molecules within the first solvation shell are so tightly bound that they induce a decrease of the effective surface charge density). Because of the weaker attraction forces between $\mathrm{Mo}^{6+}$ and the ethanol molecules the cation (symbolized by $\mathrm{X}^{+}$in the figure) cannot penetrate the second shell surrounding the $\mathrm{W}^{6+}$-AcAc complex and most likely is repelled to the air/ethanol interface (Fig. 3b). In exchange, there is a higher probability for the $\mathrm{Ti}^{4+}$ cations to penetrate the W-AcAc second solvation shell due to their stronger interaction with the solvent molecules, forming H-bonds with the ethanol molecules in the first shell or directly connecting through the $\mathrm{Cl}^{-}$anions to the $\mathrm{W}^{6+}$ cation. This explains why surface tension is more strongly affected by Mo doping than by Ti doping.

\subsection{Films morphology}

SEM images of the $\mathrm{WO}_{3}$ and of the $5 \%$ at. Ti- $\mathrm{WO}_{3}$ and $\mathrm{Mo}-\mathrm{WO}_{3}$ thin films are compared in Fig. 4. The films WT5 and WM5 show more and better defined spherical formations compared to the $\mathrm{WO}_{3}$ films (W) as a possible result of changes in the precursor evaporation rate due to surface tension variation.

Fig. 4 SEM images of the $\mathrm{WO}_{3}$ film (W) and of the Ti (WT5) and Mo (WM5)-WO 3 films.

No information related to particle shape and distribution could be drawn and this is why AFM analysis was performed. The $2 \mathrm{D}$ AFM images corresponding to a $5 \mu \mathrm{m} \times 5 \mu \mathrm{m}$ scan area $(1 \mu \mathrm{m} \times 1 \mu \mathrm{m}, 3 \mathrm{D}$ images in the insets) and the pore size distributions are presented in Fig. 5 (a, c-h) and Fig. 5b, 
respectively. The average roughness $\left(S_{a}\right)$ and surface skewness $\left(S_{\text {sk }}\right)$ were calculated (Table 1$)$ by using the NOVA dedicated software for the $1 \mu \mathrm{m} \times 1 \mu \mathrm{m}$ surface. $S_{\text {a }}$ represents the average height over a defined surface, $\quad S_{a}=\frac{1}{M N} \sum_{k=0}^{M-1} \sum_{l=0}^{N-1}\left|z\left(x_{k}, y_{l}\right)\right|$. The $\quad \mathrm{S}_{\mathrm{sk}} \quad$ is described $\quad$ by the following relation: $S_{s k}=\frac{1}{M N S_{q}^{3}} \sum_{k=0}^{M-1} \sum_{l=0}^{N-1}\left[z\left(x_{k}, y_{l}\right)\right]^{3}, \quad$ where $S_{q}$ is the root mean square roughness $\left(S_{q}=\sqrt{\frac{1}{M N} \sum_{k=0}^{M-1} \sum_{l=0}^{N-1}\left[z\left(x_{k}, y_{l}\right)\right]^{2}}\right), \mathrm{z}$ is the height in a given point $(\mathrm{x}, \mathrm{y})$, and $\mathrm{M}$ and $\mathrm{N}$ are the scan dimensions. For $S_{\mathrm{sk}}=0$ the distribuion of height on the surface is uniform; $S_{\mathrm{sk}}>0$ characterizes a plane surface with columnar structures; and when $S_{\mathrm{sk}}<0$ the planar surface is rich in pores.

The W sample (Fig. 5a), appears as a homogenous film formed of round particles interconnected through pores of $40 \mathrm{~nm}$ average size (Fig. 5b, black curve), evenly distributed on the surface as previously reported [47]. With increasing $\mathrm{Ti}$ and Mo concentration, the pore size decreases and the distribution is narrowed (Fig. 5b) indicating that particles are closer one to each other, while roughness values are diminished along with surface skewness value increase (surface richer in columnar structures than pores). The proportion of columns and pores are equilibrated for films WM2 and WM5 presenting values close to 0 .

Fig. 5 AFM images of the $\mathrm{WO}_{3}$ film -W(a), Ti - WT2 (c), WT5 (d) and WT10 (e), and Mo - WM2 (f), WM5 (g) and WM10 (h) $\mathrm{WO}_{3}$ films, and pore size distribution (b).

The surface tension of the precursor solutions decreases whit increasing the cation concentration, consequently smaller and more numerous droplets are directed towards the substrate; the solvent evaporates when approaching the substrate, strongly increasing the concentration inside the droplet, therefore, when reaching the substrate, fast nucleation occurs, with a uniform distribution of the nuclei; these can further grow to form homogenous and dense layers, characterized by low roughness.

It seems that increasing the Ti concentration in the precursor solution leads to larger particles (Fig. 5d). However, for higher doping levels particle growth is inhibited as the species diffusion at the surface is limited by layer densification or by additive segregation at the grain boundaries. For the $\mathrm{Mo}-\mathrm{WO}_{3}$ thin films, densification commences at low concentrations (as expected from the surface tension values), the morphology of sample WM2 is formed of closely packed aggregates, of various sizes. 


\subsection{Thin films structure and composition}

The XRD patterns of the $\mathrm{Ti}-\mathrm{WO}_{3}$ and $\mathrm{Mo}-\mathrm{WO}_{3}$ layers are presented next to the $\mathrm{WO}_{3}$ layer in Fig. 6a and b, respectively. All the samples present a monoclinic structure (JCPDS ICCD 89-4476), with a preferential growth along the $\left(\begin{array}{lll}2 & 0 & 0\end{array}\right)$ lattice reflection plane. Strong peaks corresponding to the substrate were also identified ( $\mathrm{SnO}_{2}$, tetragonal JCPDS ICCD 77-0451). Monoclinic $\mathrm{WO}_{3}$ with $(200)$ preferential growth was already reported by Regragui et al. [35] for films deposited at $300{ }^{\circ} \mathrm{C}$ from a solution containing $\mathrm{WCl}_{6}$ dissolved in a $1: 1 \mathrm{v} / \mathrm{v}$ ethanol: water mixture. No additional peaks corresponding to impurities were identified.

Fig. 6 XRD patterns of the $\mathrm{Ti}-\mathrm{WO}_{3}$ (a) and $\mathrm{Mo}-\mathrm{WO}_{3}$ (b) films presented next to the $\mathrm{WO}_{3}$ film.

The grain size (D) was calculated using the Scherrer formula, D $=0.9 \lambda /(\mathrm{FWHM} \cdot \cos \theta),[48]$ considering the $\left(\begin{array}{lll}2 & 0 & 0\end{array}\right)$ peak, where 0.9 is the Scherrer constant, $\lambda$ is the wavelength of the incident beam, FWHM is the full width at half maximum of the peak and $\theta$ is the Bragg angle. The lattice strain ( $\varepsilon$ ) was calculated with the Wilson formula, $\varepsilon=\mathrm{FWHM} / 4 \tan \theta$ [49] and the interplanar distance using Bragg's law. The values of the crystallite size, lattice strain and interplanar distance are gathered in Table 1.

Table 1. Crystallite size (D), interplanar distance (d) lattice strains ( $(\varepsilon)$, average roughness $\left(\mathrm{S}_{\mathrm{a}}\right)$, surface skewness $\left(S_{\mathrm{sk}}\right)$, layer thickness $(\mathrm{t})$ and band gap $\left(\mathrm{E}_{\mathrm{g}}\right)$ values of the $\mathrm{WO}_{3}$ based films.

The crystallites' size decreases and lattice strain values enhance with increasing Ti addition level. The $\mathrm{Ti}^{4+}$ cation has a different charge state comparing to $\mathrm{W}^{6+}$ therefore once inserted into the $\mathrm{WO}_{3}$ network can induce supplementary stress and crystalline disorder, associated also with an increase of oxygen vacancies concentration, explaining the larger interplanar distance values. It is obvious from the XRD patterns that at higher Ti concentration (film-WT10) layers are predominantly amorphous and this is particularly observable in the $20-40^{\circ} 2 \theta$ region, indicating that most likely the solubility limit was exceeded. For the $\mathrm{Mo}-\mathrm{WO}_{3}$ films the preferential growth direction is maintained with $\left(\begin{array}{lll}2 & 0 & 0\end{array}\right)$ and $(00$ 2) peaks even intensifying with doping concentration. This is not really unexpected as $\mathrm{Mo}^{6+}$ more easily replaces $\mathrm{W}^{6+}$ in the lattice having the same ionic radius, charge state and lattice structure; the interplanar spacing decreases from 3.680 to 3.667 for 5 and $10 \%$ at. addition levels. This means that $\mathrm{WO}_{3}$ lattice can dissolve Mo up to high contents without inducing stress, as confirmed by the lower lattice strain values, Table 1. 
To further validate the presence of $\mathrm{Ti}$ and $\mathrm{Mo}$ in the $\mathrm{WO}_{3}$ films and their corresponding oxidation states, XPS analysis was performed on the W, WM5 and WT5 films. Well-resolved doublets (Fig. 7) assigned to $\mathrm{W}^{6+} 4 \mathrm{f}_{7 / 2}$ and $4 \mathrm{f}_{5 / 2}$ components were observed at 35.5 and $37.8 \mathrm{eV}$ binding energies for sample W, 35.5 and $37.7 \mathrm{eV}$ for sample WM5 and at 35.7 and $37.8 \mathrm{eV}$ for sample WT5. There is no evidence of the presence of $\mathrm{W}$ in a lower oxidation state. A slight increase of the FWHM of the $4 \mathrm{f}_{7 / 2}$ and $4 \mathrm{f}_{5 / 2}$ peaks from 0.98 and $0.9 \mathrm{eV}$ for the un-doped sample to 1.00 and $1.01 \mathrm{eV}$ for the $5 \%$ Ti-doped $\mathrm{WO}_{3}$ layer was registered supporting the XRD data which shows that with increasing Ti doping, layer crystallinity decreases. As expected considering the oxidation state of the cations in the precursor doping salts, peaks corresponding to $\mathrm{Ti}^{4+} 2 \mathrm{p}_{3 / 2}, \mathrm{Mo}^{6+} 3 \mathrm{~d}_{5 / 2}$ and $\mathrm{Mo}^{6+} 3 \mathrm{~d}_{3 / 2}$ peaks were identified at 458.9 , 232.8 and $236.0 \mathrm{eV}$ binding energies, respectively (Fig. 7). In addition, lower oxidation states for both $\mathrm{Ti}$ and Mo were also evidenced, namely $\mathrm{Ti}^{3+} 2 \mathrm{p}_{3 / 2}, \mathrm{Mo}^{5+} 3 \mathrm{~d}_{5 / 2}$ and $\mathrm{Mo}^{5+} 3 \mathrm{~d}_{3 / 2}$ peaks at $457.3,231.4$ and $234.6 \mathrm{eV}$, respectively. The levels of $\mathrm{Ti}^{4+}, \mathrm{Ti}^{3+}$ found in the WT5 film are 2.11 and 0.20 at. \%, respectively, whereas the concentrations of $\mathrm{Mo}^{6+}$ and $\mathrm{Mo}^{5+}$ in the WM5 film are 1.30 and 0.28 at. \%, respectively. The percentage of alien cations retrieved from the XPS analysis for the $\mathrm{WO}_{3}$ layers is lower than the initial added concentration (5 at.\%).

Fig. 7 XPS spectra showing the W4f, Ti2p and Mo3d core levels for the $\mathrm{WO}_{3}(\mathrm{~W})$, and $5 \%$ at. Ti and Mo- $\mathrm{WO}_{3}$ films (WT5 and WM5).

The O1s peak (Fig. 7) was deconvoluted in four compenents: compenent I which is assigned to the exygen atoms $\left(\Theta^{2-}\right)$ that form the strong $\mathrm{W}=O$ bonds, component $\mathrm{I}$ is the results of two contributions $\mathrm{C}=\mathrm{O}$ pellution and the oxygen deficiency, component $\mathrm{III}$ is attributed to $\mathrm{C}-\mathrm{O}$ contamination, whereas the highest energy peak (component IV) is attributed to water bound at the surface of the layers $[51,52]$. By comparing the integrated areas of the peaks I and $I$, the oxygen vacancy concentration variation with doping was investigated; $\Theta_{I} / \Theta_{I}+$ II ratio values are given in Table 2 . Apparently, the oxygen vacancies concentration is higher for the WM5 layer compared to WT5 layer. XPS analysis highlights that Ti-doping enriches the surface adsorbed $\mathrm{H}_{2} \mathrm{O}$, which can scavenge the oxygen vacancies, thus explaining the slight change in oxygen deficiency. On the other hand Mo-doping reduces the water content at the surface, in agreement with the AFM pore size distribution results which show that sample WM5 has a lower porosity compared to sample WT5, thus a lower probability to adsorb water.

Fig. 7 XPS spectra of the O1s-levels for the layers W, WT5 and WM5. 
Table 2. Atomic percentages and compositional ratios for $\mathrm{WO}_{3}$ and $\mathrm{Ti} / \mathrm{Mo}-\mathrm{WO}_{3}$ layer obtained after XPS fitting.

The presence of $\mathrm{Ti}^{3+}$ might be the consequence of layer porosity which increases its reactivity. One possibility is the removing of $\left(\begin{array}{lll}1 & 1 & 0\end{array}\right)$ and $\left(\begin{array}{lll}1 & 0 & 0\end{array}\right)$ bridging oxygen by desorption during annealing according to the reaction, [50]:

$$
T i^{4+}-O-T i^{4+} \rightarrow T i^{3+}-V_{O}^{\bullet \bullet}-T i^{3+}+1 / 2 O_{2}
$$

Another possibility is the reaction of the same bridging oxygen with reducing species such as $\mathrm{H}_{2}$ and $\mathrm{C}$ during annealing $[53,54]$ :

$$
\begin{gathered}
-\mathrm{Ti} i^{4+}-\Theta=\mathrm{Ti}^{4+}+\mathrm{H}_{2} \rightarrow \mathrm{Ti}^{3+}-\otimes-\mathrm{Ti}^{3+}+\mathrm{H}_{2} \Theta \\
\mathrm{Ti} i^{4+}-\Theta-T i^{4+}+C \rightarrow T i^{3+}-\otimes-T i^{3+}+C \Theta
\end{gathered}
$$

The same phenomena could be the cause for the $\mathrm{Mo}^{6+}$ reduction to $\mathrm{Mo}^{5+}$.

\subsection{Optical properties}

The optical transmission and total reflectance (in the inset) spectra of the un-doped and Ti and Modoped films are presented in Fig. 8. Overall, the average transmission of $\mathrm{WO}_{3}$ based thin films are in between 75 and $85 \%$, with the $\mathrm{Ti}_{-}-\mathrm{WO}_{3}$ films having higher transparency. The layer having the highest reflectance is characterized by the lowest transmission level. The thin films reflectance decreases with increasing additive concentration along with roughness diminution due to solution surface tension diminution.

Fig. 8 Transmission spectra (total reflectance spectra in the inset) of the $\mathrm{WO}_{3}$ based layers. Baseline was done with the FTO substrate.

The oscillations in the transmittance spectra are caused by optical interference arising due to the difference between the refractive index of the $\mathrm{WO}_{3}$ films and the substrate and also the interference of the multiple reflections originated from the film and substrate surfaces/interfaces [55]. From the interference fringes, using the envelope method elaborated by Swanepoel $[56,57]$ the layer thickness was calculated in the weak and medium absorbing region using the following equation: 


$$
t-\frac{\lambda_{1} \lambda_{2}}{2\left(\lambda_{1} n_{2}-\lambda_{2} n_{1}\right)}
$$

where $\mathrm{T}_{M}$ and $\mathrm{T}_{\mathrm{m}}$ are the maximum and minimum transmission values at a particular wavelength, $s$ is the refractive index of the substrate (1.7), $\mathrm{n}_{1}$-and $\mathrm{n}_{2}$-are the refractive indices of two adjacent maxima which correspond to the wavelengths $\lambda_{1}$-and $\lambda_{2:}$. The band gap was evaluated from the transmittance spectra by using the Tauc relation:

$$
\alpha h v=A\left(h v-E_{g}\right)^{n}
$$

where $A$ is a constant, $h v$ is the incident photon energy, Eg is the optical energy band gap, and $\alpha$ is the absorption coefficient. The exponent value was considered $n=2$, as $\mathrm{WO}_{3}$ is an indirect band gap semiconductor. The band gap values are presented in Table 1.

Similar band gap values were obtained for samples WT2 and WT5 and a blue shift is observed for $10 \% \mathrm{Ti}$ at. levels associated with its poor crystallinity. For the $\mathrm{Mo}-\mathrm{WO}_{3}$ films the band gap is red shifted with increasing doping concentration. The band gap narrowing or widening in doped $\mathrm{WO}_{3}$ samples is also the result of the introduction of electronic states in the band gap [7, 51,52]. In spite of the fact that films WT10 and WM10 present comparable roughness values, even morphology, addition of high $\mathrm{Ti}$ at. lowers the absorption in the VIS-part of the spectra as confirmed by the $\mathrm{E}_{\mathrm{g}}$ values, resulting in higher transmission levels.

\subsection{Electrical conductivity}

\section{Current-voltage measurements}

As most of the applications are in opto-electronics, it is important to study the effect of additives on conductivity. Therefore, the current-voltage measurements were performed in dark on the $\mathrm{FTO} / \mathrm{WO}_{3}$ junctions $\left(0.15 \mathrm{~mm}^{2}\right)$, in the potential range -2 to $2 \mathrm{~V}$, and the $\mathrm{Ln}(\mathrm{I}) \mathrm{vs}$. V curve are plotted in Fig $9 \mathrm{a}$.

Fig. 9 Representation of the $\mathrm{Ln}(\mathrm{I})$ vs. V curves for the $\mathrm{WO}_{3}$ based films (a) and examples of reversed saturation current ( $\left.\mathrm{I}_{\mathrm{S}}\right)$ extrapolation from the $L n(I)$ vs. $E(V)$ curve, $H(I)$ vs. I (II) and $d V / d l n(I)$ vs. I (III)

$$
\text { plots for sample WM10 (b). }
$$

All $\mathrm{WO}_{3}$ layers exhibit rectifying behavior and possibly a p-type behaviour as previously reported $[47,53]$. Interestingly, the films stored in dry conditions (desiccator) do not present a rectifying 
behavior so we believe that the origin of this behavior is the adsorption/desorption of atmospheric oxygen or water vapors during deposition and annealing.

In $\mathrm{WO}_{3}$, thermally generated oxygen vacancies $\left(V_{o}^{\bullet \bullet}\right)$ are the most abundant native defects being responsible for the n-type conductivity of this semiconductor [54]. The formation of the double ionized oxygen vacancy is shown in eq. 1 and the resulting free electrons are considered to be localized in the conduction band (CB). During annealing in air, the majority of oxygen vacancies can be passivated by oxygen up-taking and generate positive holes lowering the n-type conductivity of $\mathrm{WO}_{3}$. Alse, during annealing in air, oxygen atoms can adsorb at the surface of $\mathrm{WO}_{3}$ and yield a tungsten vacancy and six positive holes, explaining the p-type conductivity of the $\mathrm{WO}_{3}$ films. Although inducing a significant unbalance, this reaction could be possible at the surface (being highly unlikely in the bulk film). During annealing in air oxygen can also occupy interstitial sites following an anti-Frenkel defect formation mechanism (eq. 8).

$$
\begin{gathered}
O_{0}^{x} \leftrightarrow V_{o}^{\bullet \bullet}+2 e^{-}+1 / 2 O_{2}(1) \\
\theta_{0}^{x} \leftrightarrow \theta_{i}^{\prime \prime}+V_{O}^{\bullet \bullet} \\
1 / 2 \theta_{2} \longrightarrow V_{W}^{6 /}+\theta_{O}^{X}+6 h^{\bullet}
\end{gathered}
$$

Additionally, because metal oxides are exposed to the atmospheres eontaining water vapors during cooling, oxygen vacancies can be filled by water molecules according to eq. 2, forming hydroxide ions $\left(\mathrm{OH}_{0}^{\bullet}\right)$ on normal oxygen sites [55].

$$
\mathrm{H}_{2} \mathrm{O}+\mathrm{V}_{0}^{\bullet \bullet}+\mathrm{O}_{0}^{x} \rightarrow 2(\mathrm{OH})_{0}^{\bullet}(2)
$$

However, fabrication processes developed under vacuum should be avoided as they increase the production cost. This unusual change in the semiconducting behavior was already observed for $\mathrm{WO}_{3}$ materials exposed to different gases and explained by the formation of a surface inversion layer [56,57].

None of the films have higher forward conductivity than W, with $\mathrm{Mo}-\mathrm{WO}_{3}$ films showing better conductivity than $\mathrm{Ti}_{-} \mathrm{WO}_{3}$ films (Fig. 9a). The WT2 and WT5 films have narrower band gap, most probably due to a higher oxygen vacancy concentration compared to the $\mathrm{Mo}-\mathrm{WO}_{3}$ films (WM2 and WM5), which explains also their poor p-type conductivity. The lowest conductivity corresponds to the layer with the highest band gap and poor crystallinity, sample WT10. 
The current I through the junction under low bias voltage, according to the thermionic emission model considering the series resistance $\mathrm{R}_{\mathrm{s}}$, is given by the following relation [58]:

$$
I=I_{S}\left\{\exp \left[q\left(V-I R_{S}\right) / n k T\right]-1\right\}(3)
$$

and

$$
I_{S}=A A^{*} T^{2} \exp \left[-q \phi_{b} / k T\right](4)
$$

where $\mathrm{q}$ is the charge, $\mathrm{V}$ is the applied voltage, $\mathrm{n}$ is the diode ideality factor, $\mathrm{k}$ is the Boltzmann constant, $\mathrm{T}$ is the temperature in $\mathrm{K}, \Phi_{\mathrm{b}}$ is the effective barrier height, $\mathrm{A}$ is the junction area, $\mathrm{A}^{*}$ is the effective Richardson constant [considered $1.20173 \times 10^{6} \mathrm{~A} \mathrm{~m}^{-2} \mathrm{~K}^{-2}$ ] and $\mathrm{IS}_{\mathrm{S}}$ is the reverse saturation current. In the low voltage bias, the term $\mathrm{IR}_{\mathrm{S}}<<\mathrm{V}$, therefore the following relation can be written:

$$
\ln I=\ln I_{S}+(q V / n k T)(5)
$$

The $\ln (\mathrm{I})-\mathrm{V}$ curves obtained using the $\mathrm{I}-\mathrm{V}$ experimental data are presented in Fig. $9 \mathrm{~b} I$. Based on eq. (5), the reversed saturation current $\mathrm{I}_{\mathrm{S}}$ was evaluated from the intercept of the strait-line in the downward curvature region [59] with the $\mathrm{Y}$ axis at $\mathrm{V}=0$. The $\ln (\mathrm{I})-\mathrm{V}$ characteristics of the samples deviate from linearity suggesting high series resistance, and Cheung's functions [60] were used (eq. 6, 7 and 8) for the correct assessment of the ideality factor $n$, series resistance $R_{S}$ and effective barrier height $\Phi_{\mathrm{b}}$.

$$
\begin{gathered}
d V / d \ln (I)=n k T / q+I R_{S}(6) \\
H(I)=V+n k T / q \ln \left(I / A A^{*} T^{2}\right) \\
H(I)=n \phi_{b}+I R_{S}(8)
\end{gathered}
$$

The Rs and $n$ values were determined from the slope and intercept of the $d V / d \ln (\mathrm{I})$ vs. I plot (Fig. 9bII) whereas the barrier height $\Phi_{b}$ was calculated from the $H(I)$ vs. I plot (Fig. 9bIII) using the already determined $n$ value. The turn-on voltage $\mathrm{V}_{\mathrm{D}}$ and the current corresponding to the turn-on voltage $\mathrm{I}_{\mathrm{D}}$ for all the films were also extracted from the I-V curve. The results are gathered in Table 2.

Table 2. Turn on voltage $\left(V_{D}\right)$ and corresponding current $I_{D}$, ideality factor $(n)$, reverse saturation current $\left(I_{S}\right)$, series resistance $\left(R_{s}\right)$, barrier height determined from I-V measurements $\left(\Phi_{b}-I V\right)$ and from $\mathrm{C}-\mathrm{V}$ measurements $\left(\Phi_{\mathrm{b}}-\mathrm{CV}\right)$. 
The $\mathrm{WO}_{3}$ film is characterized by the best ideality factor (close to 1). The ideality factor of the WT2 film could not be calculated because of poor rectifying behavior, whereas for the WT10 film a high deviation from ideality was observed. As a matter of fact, the WT2 film shows a transitory behavior between $\mathrm{n}$ and p-type conductivity, as Ti replaces $\mathrm{W}$ in the lattice creating oxygen vacancies (eq. 9).

$$
\mathrm{TiO}_{2} \stackrel{\mathrm{WO}_{3}}{\longrightarrow} \mathrm{Ti}_{W}^{2 /}+2 \mathrm{O}_{O}^{X}+V_{O}^{\bullet \bullet}(9)
$$

Even if surface processes annihilate part of these vacancies, the turn on towards a p-type behavior is not realized. A $5 \%$ at. Ti content in the precursor solution gives the optimum p-type conductivity among the $\mathrm{Ti}^{-} \mathrm{WO}_{3}$ films, mostly because of vacancy passivation by oxygen (eq. 1) and water (eq. 2) up taking. Although with lower thermodynamic probability, other reactions are also possible at excess doping with $\mathrm{Ti}^{4+}$ when interstitial sites can be occupied, leading to the introduction of acceptor levels $\left(T i_{i}^{4 \bullet}\right)\left(\right.$ ec. 10) close to the upper edge of the valence band into the $\mathrm{WO}_{3}$ band gap:

$$
3 \mathrm{TiO}_{2} \stackrel{2 \mathrm{WO}_{3}}{\longrightarrow} 2 \mathrm{Ti}_{W}^{2 \prime}+\mathrm{Ti}_{i}^{4 \bullet}+6 \mathrm{O}_{O}^{X}
$$

In addition the ionic defects, at higher temperatures Ti concentration, electronic compensation might be the predominant process, with holes balancing the introduction of titanium donor levels in the energy gap (reaction 11).

$$
\mathrm{TiO}_{2} \stackrel{\mathrm{WO}_{3}}{\longrightarrow} \mathrm{Ti}_{W}^{2 \prime}+2 \mathrm{O}_{O}^{X}+2 h^{\bullet}
$$

The Kroger-Vink notation was used [61], where $O_{0}^{x}$ represents an oxygen atom in an oxygen lattice site with neutral charge, $V_{0}^{\bullet \bullet}$ is the double positively charged oxygen vacancy, $T i_{i}^{\cdot \bullet}$ is titanium interstitial with $4+$ positive charge, $T i_{W}^{2 /}$ is a titanium atom replacing $\mathrm{W}$ with -2 negative charge with respect to the perfect lattice.

However, when Ti concentration is further increased, an excess amount of interstitials is generated, causing band gap widening (Table 1), enhancing eharge imbalance and lattice disorder, as revealed by the XRD analysis, with negative effects on conductivity. Also at higher doping concentrations the double charged oxygen vacancies could mainly become the charge compensating defects at the expense ef electron holes.

Good rectification rates were obtained for the films WM2, WM5, WM10 ( $n=1.2-1.3$, Table 2) which are characterized by the lowest lattice stress values, with the best turn on current obtained for the WM2 film $\left(-3.0 \cdot 10^{-5} \mathrm{~A}\right)$, which then decreases in good agreement with a series resistance enhancement. The 
reverse leakage current decreases with increasing $\mathrm{Mo}$ and $\mathrm{Ti}$ amounts, and maintains rather high values. According to Bhatnagar et al. [62] and Weber et al. [63] the high values of $I_{s}$ are the effect of surface states and defects which enhance localized barrier height.

As the AFM images show the pore and particle size decrease with Ti and Mo level and so is the films surface reactivity, consequently the contribution of this factor to conductivity is diminished and more likely the generated oxygen vacancies are responsible for the p-type conductivity loss in the heavily doped Ti, Mo- $\mathrm{WO}_{3}$ films.

The adsorption of gases or water on the $\mathrm{WO}_{3}$ surface influence the electrical properties of the films and the extent at which this process might happen depends on the surface morphology. The chemiserption of oxygen from air during annealing is favorable on porous layers; the more oxygen is absorbed the higher the amount of oxygen vacancies that can be passivated and the higher the concentration of holes participating in the conduction. Oxygen can suppress the formation of interstitial-oxygen $\left(\theta_{i}^{\prime \prime}\right)$ tungsten vacancies $\left(V_{W}^{6 /}\right)$ dener states so that the accepter states $\left(V_{O}^{\bullet \bullet}\right)$ cannot be compensated, and the structure enhances its p-type conductivity. The W, WT5, WM2, WM5 and WM10 films-seem to have suitable particle sizes and interparticle distances (pores) to support this process, explaining their higher p-type conductivity.

The conductivity of doped $\mathrm{WO}_{3}$-depends on the competition between the reactions that occur at acceptor $\left(F i_{i}^{4 \bullet}, V_{O}^{\bullet \bullet}\right)$ and donor levels $\left(T_{i}^{2 /},-\Theta_{i}^{\prime \prime}\right)$, but mainly on the variations in the oxygen vacancy eoncentration, which is influenced by films sufface reactivity with sorrouding atmosphere. Under thermal annealing at low $\mathrm{Ti}$ content $(2 \%)$, the oxygen interstitials and tungsten vacancies are high enough to compensate and exceed the oxygen vacancy concentration thus decreasing the $p$-type eonductivity.

\section{Mott-Schottky analysis}

Doping modifies the band gap energy and is expected to modify the Fermi energy by modifying the carrier charge density. Mott-Schottky measurement was performed for calculating the acceptor density and the flat band potential. The amplitude of the sinusoidal voltage was $25 \mathrm{mV}$ and the measurements were performed at room temperature in open air. The $\mathrm{FTO} \mathrm{WO}_{3}$ junction exhibits Mott-Schottky behavior, following the relation between $C_{s c}$ and applied voltage V:

$$
1 / C_{s c}^{2}=\left(2 / e \varepsilon_{0} \varepsilon_{r} N_{a} A^{2}\right)\left(V+V_{F B}\right)
$$


where: $C_{\mathrm{sc}}$ is the differential capacitance of the space charge region, $N_{\mathrm{a}}$ the acceptor density, $\varepsilon_{0}$ the permittivity of vacuum $\left(8.854 \cdot 10^{-12} \mathrm{~F} \mathrm{~m}^{-1}\right), \varepsilon_{\mathrm{r}}$ the relative dielectric constant of $\mathrm{WO}_{3}(50,[64]), A$ is the surface area of the semiconductor contact $\left(0.15 \mathrm{~mm}^{2}\right), V$ the electrode potential, $V_{\mathrm{FB}}$ the flat band potential and $k, T, e$ have the usual meaning.

The Mott-Schottky analysis confirms the p-type semiconducting behavior of the $\mathrm{WO}_{3}$ layers. In the graphs of $1 / C_{s c}^{2}$ versus $\mathrm{E}$ (Fig. 10), the voltage axis intercepts gives the flat band potential, $\mathrm{V}_{\mathrm{FB}}$, whereas the slope of the straight line portions of the Mott-Schottky plots were used to determine the acceptors' concentration, $\mathrm{N}_{\mathrm{a}}$, and values are shown in Table 2. The highest acceptor density is obtained for the WT5 film $\left(7.58 \cdot 10^{15} \mathrm{~cm}^{-3}\right)$, which explains its higher conductivity with respect to the other Ti$\mathrm{WO}_{3}$ films. A comparison between $\mathrm{Ti}$ and $\mathrm{Mo}-\mathrm{WO}_{3}$ thin films is not possible because of different ionization mechanism and energies of the generated impurity levels. Using the band gap values (Table 1), the position of the Fermi energy with respect to the top of the valence band can be calculated, [65]:

with

$$
E_{F}-E_{V}=K T \ln \left(N_{V} / N_{a}\right)
$$

$$
N_{V}=\left(2 / h^{3}\right)\left(2 \pi m_{h}^{*} k T\right)^{3 / 2}
$$

where $\mathrm{N}_{\mathrm{V}}$ is the effective density of states in $\mathrm{WO}_{3}$ valence band, $m_{h}^{*}=0.56 \mathrm{~m}_{0}$ the effective mass of holes and $m_{0}$ the rest mass of the electron $\left(9.1 \cdot 10^{-31} \mathrm{~kg}\right)$. The value obtained for $\mathrm{N}_{\mathrm{V}}$ was $1.05 \cdot 10^{19} \mathrm{~cm}^{-3}$. The barrier height can be calculated using the following formula:

$$
\phi_{b}=V_{F B}+\left(E_{F}-E_{V}\right)
$$

The carrier concentration, $\mathrm{N}_{\mathrm{a}}$, the $\mathrm{E}_{\mathrm{F}}-\mathrm{E}_{\mathrm{V}}$ and the barrier height values are gathered in Table 2 .

The barrier height values obtained from the $\mathrm{C}-\mathrm{V}$ curves are higher than the barrier heights derived from the I-V measurements. This discrepancy is probably due to an interfacial layer or trapped states in the semiconductor. This result is in agreement with other reports $[66,67]$.

Fig. 10 Mott-Schottky plots of the $\mathrm{WO}_{3}$ based films.

The band diagram of the $\mathrm{FTO} / \mathrm{WO}_{3}$ junction was modeled for explaining the conducting behavior in case of forward and reverse biasing. The position of the valence and conduction bands of the $\mathrm{WO}_{3}$ films where calculated using the equation, [68]:

$$
E_{V B}=\chi_{\text {semiconductor }}-E_{e}+0.5 E_{g}
$$


where: $E_{V B}$ is the VB edge potential, $\chi_{\text {semiconductor }}$ is the semiconductor electronegativity, $E_{e}$ is the energy of free electrons vs. SHE, $\mathrm{E}_{\mathrm{g}}$ is the band gap energy of the semiconductor (experimentally measured), and $\mathrm{E}_{\mathrm{CB}}$ can be calculated by:

$$
E_{C B}=E_{V B}-E_{g}
$$

The absolute semiconductor electronegativity $\chi_{\text {semiconductor }}(e V)$ and the absolute cationic electronegativity $(\mathrm{eV}) \chi_{\text {cation }}(\mathrm{eV})$ can be calculated using the following two relations [69], where $\chi_{\text {cation }}(P$. . .) represents the cationic electronegativity (P.u., Pauling units).

$$
\begin{gathered}
\chi_{\text {semiconductor }}(e V)=0.45 \cdot \chi_{\text {cation }}(e V)+3.36 \\
\chi_{\text {cation }}(e V)=2.976 \chi_{\text {cation }}(P . u)+0.612
\end{gathered}
$$

The band diagram of the $\mathrm{FTO} / \mathrm{WO}_{3}$ junction is presented in Fig. 11, where $\mathrm{q} \Phi_{\mathrm{S}}$ is the semiconductor work function, $\mathrm{qX}_{\mathrm{S}}$ is semiconductor affinity and $\mathrm{q} \Phi_{\mathrm{m}}$ is metal work function $(5.10 \mathrm{eV})$. (Fig. 11, frame 2).

Fig. 11 Band diagram of FTO/ $\mathrm{WO}_{3}$ junction before contact (1), at thermal equilibrium (2), under forward bias (3) and under reversed bias (4).

When put into contact electrons can lower their energy in FTO by flowing into the conduction band of p- $\mathrm{WO}_{3}$ until the chemical potential of the semiconductor equals the Fermi energy of the FTO (Fig. 11, frame $1 \rightarrow 2$ ). The resulting $q \Phi_{b}$ represents thus the Schottky barrier which is higher than the flat band potentials $\mathrm{qV}_{\mathrm{FB}}$. At forward bias (Fig. 11, frame 3) the Fermi level of the FTO is raised in energy above the bulk Fermi level in the semiconductor, which lowers the potential drop across the depletion layer to a value $\mathrm{V}_{\mathrm{FB}}-\mathrm{V}$ and increases the hole current from the semiconductor to the FTO. If a reverse bias is applied (Fig. 11, frame 4), the Fermi level of FTO is lowered below that of the semiconductor, and the barrier height for holes is increased on the semiconductor side by the amount of the reverse bias $\mathrm{V}_{\mathrm{FB}}+\mathrm{V}$ decreasing the hole current.

The suitable band alignment (Fermi level equalization) in multilayered structures used in photoconversion applications such as dye sensitized solar cells or photoelectrochromic devices determine the conversion efficiency so the knowledge of the Fermi level position is important. In dye sensitized solar cells the working voltage produced by the device is the difference between the Fermi level of the oxide and the redox potential of the electrolyte [70]. 


\section{Photoconductivity}

The change of current measured at a constant voltage of $0.01 \mathrm{~V}$ under illumination is shown in Fig. 12. The samples were left to equilibrate for 20s, then illumination was turned on and, because the current did not have a sharp increase/decrease and did not reach a saturation point at longer times, it was turned off at the same time for all the samples, after 40s, and was allowed to decrease for about 100s. The incident photon to electron conversion efficiency (IPCE) was calculated using the formula:

$$
I P C E=1240 \cdot I / \lambda \cdot J_{\text {light }}
$$

where $\mathrm{I}$ is the maximum photocurrent density obtained after $40 \mathrm{~s}$ illumination, $\lambda$ the incident light wavelength $(390 \mathrm{~nm})$, and $J_{\text {light }}$ is the measured irradiance $\left(17 \mathrm{mWcm}^{-2}\right)$. The IPCE results are shown in the inset of Fig. 12.

Fig. 12 Photocurrent curves for the $\mathrm{WO}_{3}$ based films with calculated IPCE values (in \%) in the inset.

Before irradiation a very small current runs through the $\mathrm{WO}_{3}$ film, then the current increases slowly when the light is switched on and a residual photocurrent is observed after the light is turned off. The intensity of the photogenerated current depends upon the flat band potential, the larger the value of flat band potential, the greater the photoconversion efficiency will be [65]. The highest IPCE values were obtained for films WT2, WT5, WM5 and WM10 because they have band gaps close or equal to W for which the wavelength was calibrated for maximum photoresponse. The photocurrent density increases with Mo concentration which is in good agreement with rising $\mathrm{V}_{\mathrm{FB}}$ values. Contrary, for Ti doping, the IPCE decreases with increasing concentration, with sample WT10 having the lowest efficiency due to poor absorption of incident light as it exhibits the highest band gap widening $\left(\mathrm{E}_{\mathrm{g}}=2.77 \mathrm{eV}\right)$ and the lowest $\mathrm{V}_{\mathrm{FB}}(1.36 \mathrm{eV})$. The donor or acceptor levels present in the bad gap can act as traps or as charge transfer promoters influencing the photo-conversion efficiency.

\section{Conclusions}

This paper is focused on analyzing the influence of additives ( $\mathrm{Ti}$ and Mo in 2, 5 and 10 at. \% levels) on the opto-electronic properties of $\mathrm{WO}_{3}$ thin films deposited by spray pyrolysis. The additives modify the crystalline structure and morphology of the native layer and in correlation with the modification of the solution surface tension, which is dependent on doping cation reactivity with the already formed $\mathrm{W}^{6+}$ - 
AcAc complexes. Solution surface tension reduces with increasing foreign cation concentration, with the lowest values for the Mo-contaning solutions, being responsible for the $\mathrm{WO}_{3}$ films densification. Xray analysis shows that $\mathrm{Ti}$ has a detrimental effect on layers structure (increasing disorder/stress and layer amorphization) as opposed to Mo which improves the crystalline order. as consequence of layer interaction with the surrounding atmosphere (i.e. oxygen and water adsorption during annealing/cooling). Moreover, a close relation between conductivity and these surface processes was established as they mainly have an effect on the oxygen vacancy concentration.

The $\mathrm{FTO} / \mathrm{WO}_{3}$ junction was successfully used as diagnosing tool for determining the quality of the $\mathrm{WO}_{3}$ films, given that its properties (i.e. barrier height, ideality factor and series resistance) were found strongly related to the layer structure, morphology and composition. Good rectification rates were obtained for the $\mathrm{Mo}-\mathrm{WO}_{3}$ films which are characterized by the lowest lattice stress and surface resistance values. $\mathrm{WO}_{3}$ based films exhibit a p-type semiconducting behavior, as confirmed also by the Mott-Schottky analysis, with lower p-type conductivity for the $\mathrm{Ti}-\mathrm{WO}_{3}$ films. The band diagram of the FTO/ $\mathrm{WO}_{3}$ junction was modeled to explain the conductivity under forward and reverse bias. Changes in conductivity were attributed to the evolution of oxygen vacancy concentration at the film surface due oxygen/water adsorption from the atmosphere. For heavily doped $\mathrm{WO}_{3}$ films the contribution of these surface processes to the overall conductivity is reduced since surface reactivity is lost by densification. The XPS analysis confirmed the presence of the cations in the valence states corresponding to the precursor salts, but also in lower valence states $\left(\mathrm{Ti}^{3+}\right.$ and $\left.\mathrm{Mo}^{5+}\right)$. Doping allows tuning the optoelectronic properties, but the output criterion/criteria has/have to be defined since the optimized deposition depends on the targeted application. Good conductivity (ideality factors close to 1) can be obtained for $2 \%$ at. $\mathrm{Mo}^{-\mathrm{WO}_{3}}$ layers characterized by high crystallinity and layer uniformity, the photoconductivity can be significantly increased by $2 \%$ at. Ti addition, transmission of the $\mathrm{WO}_{3}$ layers in the visible region can be increased by adding Ti.

Acknowledgements:

This work was supported by the Sectoral Operational Programme Human Resources Development (SOP HRD), ID59321, financed from the European Social Fund and by the Romanian Government. We gratefully acknowledge Christine Labrugere (PLACAMAT Bordeaux) for XPS analysis and Guy Campet for fruitful discussions.

References 
1. J.L. Solis, S. Saukko, L. Kish, C.G. Granqvist, V. Lantto, Semiconductor gas sensors based on nanostructured tungsten oxide, Thin Solid Films, 391 (2001) 255-260.

2. S.H. Lee, R. Deshpande, P.A. Parilla, K.M. Jones, B. To, A.H. Mahan, A.C. Dillon, Crystalline $\mathrm{WO}_{3}$ nanoparticles for highly improved electrochromic applications, Adv. Mater., 18 (2006) 763766.

3. A. Hameed, M.A. Gondal, Z.H. Yamani, Effect of transition metal doping on photocatalytic activity of $\mathrm{WO}_{3}$ for water splitting under laser illumination: role of 3d-orbitals, Catal. Commun., 5 (2004) 715-719.

4. M. Hepel, S. Hazelton, Photoelectrocatalytic degradation of diazo dyes on nanostructured $\mathrm{WO}_{3}$ electrodes, Electrochim. Acta, 50 (2005) 5278-5291.

5. A. Enesca, A. Duta, J. Schoonman, Influence of talantulum dopant ions $\left(\mathrm{Ta}^{5+}\right)$ on the efficiency of the tungsten trioxide photoelectrode, Phys. Stat. Sol. (a), 205 (2008) 2038-2041.

6. J.W. Tang, D.F. Wang, Z.G. Zou, J.H. Ye, Modification of photophysical properties of $\mathrm{WO}_{3}$ by doping different metals, Mater. Sci. Forum, 423-424 (2003) 163-166.

7. P. Maruthamuthu, M. Ashokkumar, Doping effects of transition metal ions on the photosensitization of $\mathrm{WO}_{3}$ Particles, Sol. Energ. Mater. 17 (1988) 433-438 433.

8. M. Radecka, P. Sobas, M. Wierzbicka, M. Rekas, Photoelectrochemical properties of undoped and Ti-doped $\mathrm{WO}_{3}$, Physica B, 364 (2005) 85-92.

9. R. Solarska, B.D. Alexander, A. Braun, R. Jurczakowski, G. Fortunato, M. Stiefel, T. Graule, J. Augustynski, Tailoring the morphology of $\mathrm{WO}_{3}$ films with substitutional cation doping: Effect on the photoelectrochemical properties, Electrochim. Acta 55 (2010) 7780-7787.

10. S.R. Bathe, P.S. Patil, Influence of $\mathrm{Nb}$ doping on the electrochromic properties of $\mathrm{WO}_{3}$ films, J. Phys. D, 40 (2007) 7423-7431.

11. S. R. Bathe, P.S. Patil, Titanium doping effects in electrochromic pulsed spray pyrolysed $W_{3}$ thin films, Sol. State Ion., 179 (2008) 314 323. P.S. Patil, S.H. Mujawar, A.I. Inamdar, P.S. Shinde, H.P. Deshmukh, S.B. Sadale, Structural, electrical and optical properties of $\mathrm{TiO}_{2}$ doped $\mathrm{WO}_{3}$ thin films App. Surf. Sci., 252 (2005) 1643-1650.

12. J.M. O-Rueda de León, D.R. Acosta, U. Pal, L. Castaneda, Improving electrochromic behavior of spray pyrolised $\mathrm{WO}_{3}$ thin solid films by Mo doping, Electrochim. Acta, 56 (2011) 2599-2605.

13. A. Rougier, A. Blyr, Electrochromic properties of vanadium tungsten oxide thin films grown by pulsed laser deposition, Electrochimica Acta, 46 (2001) 1945-1950.

S. Sate, Y. Seino, Electrochromism in evaporated $\mathrm{WO}_{3}-\mathrm{MoO}_{3}-\mathrm{V}_{2} \mathrm{O}_{5}$-Films, Electronics Commmnity of Japan, 65 C (1982) 104111.

N. Ozer, C.M. Lampert, Electrochromic performance of sol-gel deposited $\mathrm{W}_{3}-\mathrm{V}_{2} \mathrm{O}_{5}$ films, Thin Solid Films, 349 (1999) 205211.

14. A. Rougier, A. Blyr, J. Garcia, Q. Zhang, S.A. Impey, Electrochromic W-M-O (M=V, Nb) sol-gel thinfilms: a way to neutral colour, Sol. Energy Mater.Sol. Cells, 71 (2002) 343-357.

15. A. Pennisi, F. Simone, Electrochromic Properties of Tungsten-Molybdenum Oxide Electrodes, Sol. Energy Mater. Sol. Cells, 28 (1992) 233-247.

K.A. Gesheva, T. Ivanova, A low temperature atmospheric pressure CVD process for growing thin films of $\mathrm{MoO}_{3}$ and $\mathrm{MoO}_{3}-\mathrm{WO}_{3}$ for electrochromic device applications, Chemical Vapor Deposition, 12 (2006) 231238.

16. A. Subrahmanyam, A. Karuppasamy, Optical and electrochromic properties of oxygen sputtered tungsten oxide $\left(\mathrm{WO}_{3}\right)$ thin films, Sol. Energy Mater. Sol. Cells, 91 (2007) 266-274.

17. E. Washizu, A. Yamamoto, Y. Abe, M. Kawamura, K. Sasaki, Optical and electrochromic properties of RF reactively sputtered $\mathrm{WO}_{3}$ films, Sol. State Ion., 165 (2003) 175-180. 
18. M. Stankova, X. Vilanova, E. Llobet, J. Calderer, C. Bittencourt, J.J. Pireaux, X. Correig, Influence of the annealing and operating temperatures on the gas-sensing properties of rf sputtered $\mathrm{WO}_{3}$ thinfilm sensors, Sens. Actuators B, Chem., 105 (2005) 271-277.

19. A.H. Jayatissa, S.T. Cheng, T. Gupta, Annealing effect on the formation of nanocrystals in thermally evaporated tungsten oxide thin films, Mater. Sci. Eng. B, 109 (2004) 269-275.

20. I. Porqueras, E. Bertran, Efficiency of Li doping on electrochromic $\mathrm{WO}_{3}$ thin films, Thin Solid Films, 377(378) (2000) 129-133.

21. R.E. Tanner, A. Szekeres, D. Gogova, K. Gesheva, Study of the surface roughness of CVDtungsten oxide thin films, Appl. Surf. Sci., 218 (2003) 163-169.

22. K.A. Gesheva, G. Popkirov, M. Ganchev, E. Tzvetkova, Electrochromic properties of atmospheric $\mathrm{CVD} \mathrm{MoO}_{3}$ and $\mathrm{MoO}_{3}-\mathrm{WO}_{3}$ films and their application in electrochromic devices, Mater. Sci. Eng. B, 119 (2005) 232-239.

23. R. Vijayalakshmi, M. Jayachandran, C. Sanjeeviraja, Structural, electrochromic and FT IR studies on electrodeposited tungsten trioxide films, Curr. Appl. Phys., 3 (2003) 171 175. G. Leftheriotis, P. Yianoulis, Development of electrodeposited WO3 films with modified surface morphology and improved electrochromic properties, Solid State Ionics, 179 (2008) 2192-2197.

24. M. Giannouli, G. Leftheriotis, The effect of precursor aging on the morphology and electrochromic performance of electrodeposited tungsten oxide films. Sol. Energy Mater. Sol. Cells, 95 ( 2011) 1932-1939.

25. Y.S. Krasnov, G.Y. Kolbasov, Electrochromism and reversible changes in the position of fundamental absorption edge in cathodically deposited amorphous $\mathrm{WO}_{3}$, Electrochim. Acta, 49 (2004) 2425-2433.

26. M. Deepa, T.K. Saxena, D.P. Singh, K.N. Sood, S.A. Agnihotry, Spin coated versus dip coated electrochromic tungsten oxide films: Structure, morphology, optical and electrochemical properties, Electrochim. Acta, 51 (2006) 1974-1989.

27. A. Patra, K. Auddy, D. Ganguli, J. Livage, P.K. Biswas, Sol-gel electrochromic $\mathrm{WO}_{3}$ coatings on glass, Mater. Lett., 58 (2004) 1059-1063.

28. I. Bostan, V. Dulgheru, I. Sobor, V. Bostan, A. Sochireanu, Sisteme de conversie a energiilor regenerabile, Editura “TEHNICO-INFO”, Chişinău, 2007.

29. E. Chifu, Chimie coloidală, Editura Didactică şi Pedagogică, Bucureşti, 1969.

30. P.S. Patil, Versatility of chemical spray pyrolysis technique, Materials Chemistry and Physics, 59 (1999) 185-198.

31. R. Sivakumar A. Moses Ezhil Raj, B. Subramanian, M. Jayachandran, D.C. Trivedi, C. Sanjeeviraja, Preparation and characterization of spray deposited n-type $\mathrm{WO}_{3}$ thin films for electrochromic devices, Mat. Res. Bull., 39 (2004) 1479-1489.

32. A. Enesca, A. Duta, S. Manolache, The influence of defects on the conduction in photoelectrodes used for water splitting, J. Optoelectron. Adv. Mater., 9 (2007) 1630-1632.

33. S.B. Sadale S.M. Chaqour, O. Gorochov, M. Neumann-Spallart, Photoelectrochemical and physical properties of tungsten trioxide films obtained by aerosol pyrolysis, Mat. Res. Bull., 43 (2008) 14721479.

34. J.M. Ortega, A.I. Martınez, D.R. Acosta, C.R. Maganaet, Structural and electrochemical studies of $\mathrm{WO}_{3}$ films deposited by pulsed spray pyrolysis, Sol. Energy Mater. Sol. Cells, 90 (2006) 24712479.

35. M. Regragui M. Addou, A. Outzourhit, J.C. Bernéde, Elb. El Idrissi, E. Benseddik, A. Kachouane, Preparation and characterization of pyrolytic spray deposited electrochromic tungsten trioxide films, Thin Solid Films, 358 (2000) 40-45. 
36. A. Enesca, A. Duta, Tailoring $\mathrm{WO}_{3}$ thin layers using spray pyrolysis technique, Phys. Stat. Sol. (c), 5 (2008) 3499-3502.

37. L.M. Bertus, C. Faure, A. Danine, C. Labrugere, G. Campet, A. Rougier, A. Duta, Synthesis and characterization of $\mathrm{WO}_{3}$ thin films by surfactant assisted spray pyrolysis for electrochromic applications, Mat chem. Phys., 140 (2013) 49-59.

38. D. Perniu, A. Duta, L. Isac, A. Enesca, Solar Energy Materials Obtained by Spray Pyrolysis Deposition, http://www.romnet.net/ro/seminar16martie2010/lucrari_extenso/Anca\%20Duta\%5D.pdf

39. P.C. Hiemenz, R. Rajagopalan, Principles of Colloid and Surface Chemistry, Ed. Wiley, 3th edition, 1997, p. 262

40. J.C. Viguie, J. Spitz, Chemical vapor deposition at low temperatures, J. Electrochem. Soc., 122(4) (1975) 585-588.

41. R. Swanepoel, Determination of the thickness and optical constants of amorphous silicon, J. Phys. E, 16 (1983) 1214-1222.

42. R. Tuckermann, Surface tension of aqueous solutions of water-soluble organic and inorganic compounds, Atm. Environment, 41 (2007) 6265-6275.

43. Z. Li, A.L.Williams, M.J. Rood, Influence of soluble surfactant properties on the activation of aerosol particles containing inorganic solute, J. Atm. Sci., 55 (1998) 1859-1866.

44. G.Kiss, E.Tombácz, H. Hansson, Surface tension of humic-like substances in the aqueous extract of tropospheric fine aerosol. J. Atm. Chem., 50 (2005) 279-294.

45. P.B. Peterson, R. J. Saykally, Adsorption of ions to the surface of dilute electrolyte solutions: the Jones-Ray effect revisited, J. Am. Chem. Soc., 127 (2005) 15446-15452.

46. R.D. Shannon, Revised effective ionic radii and systematic studies of interatomic distances in halides and chalcogenides, Acta. Cryst., A32 (1976) 751-767.

47. L. M. Bertus, A. Enesca, A. Duta, Influence of spray pyrolysis deposition parameters on the optoelectronic properties of $\mathrm{WO}_{3}$ thin films, Thin Solid Films, 520 (2012) 4282-4290.

48. M. Deepa, A.K. Srivastava, S.N. Sharma, Govind, S.M. Shivaprasad, Microstructural and electrochromic properties of tungsten oxide thin films produced by surfactant mediated electrodeposition, App. Surf. Sci., 254 (2008) 2342-2352.

49. H. Cesiulis, O. Bersirova, A. Valiūnienè, I. Prosyčevas, G. Baltrūnas, Structural and morphological study of silver electrodeposits, Mater. Sci., 10 (2004) 142-146.

J. Clatot, G. Campet, A. Zeinert, C. Labrugere, M. Nistor, A. Rougier, Low temperature Si doped ZnO thin films for transparent conducting oxides, 95 (2011) 23572362.

G. Leftheriotis, S. Papaefthimiou, P. Yianoulis, A. Siokou, D. Kefalas, Structural and electrochemical properties of opaque sol gel deposited WO3 layers, App. Surf. Sei., 218 (2003) 275-280.

50. You Z.Z., Combined AFM, XPS, and contact angle studies on treated indium-tin-oxide films for organic light-emitting devices, Materials Letters, 61 (2007) 3809-3814.

J. Strunk, C. William, A.T. Bell, A Study of oxygen vacancy formation and annihilation in submonolayer coverages of $\mathrm{TiO}_{2}$-dispersed on MCM-48, J. Phys. Chem. C, 114 (2010) 16937 16945.

K.J. Lethy, D. Beena, V.P. Mahadevan Pillai, Structural, optical and morphological studies on laser ablated nano structured $\mathrm{WO}_{3}$ thin films, Appl. Surf. Sci., 254 (2008) 23692376.

L.M. Bertus, A. Duta, Synthesis of $\mathrm{WO}_{3}$ thin films by surfactant mediated spray pyrolysis, Ceram. Int., 38 (2012) 2873-2882.

51. W.Li, Y. Wang, H. Lin, S. Ismat Shah, C.P. Huang, D.J. Doren, Sergey A. Rykov, J.G. Chen, M.A. Barteau, Band gap tailoring of $\mathrm{Nd}^{3+}$-doped $\mathrm{TiO}_{2}$ nanoparticles, Appl. Phys. Lett., 83 (2003) 41434145. 
52. A. Kudo, R. Niishiro, A. Iwase, H. Kato, Effects of doping of metal chations on morphology, activity, and visible light response of photocatalysts, Chem. Phys., 339 (2007) 104-110.

53. B.G. Yacobi, Semiconductor Materials. An Introduction to Basic Principles, Kluwer Academic Publishers, New York, 2003.

54. S.K. Deb, Opportunities and challenges in science and technology of $\mathrm{WO}_{3}$ for electrochromic and related applications, Sol. Energy Mater. Sol. Cells, 92 (2008) 245-258.

55. E. Konstantinova, J. Weidmann, T.H. Dittrich, Influence of adsorbed water and oxygen on the photoluminescence and EPR of Por-TiO 2 (Anatase), J. Porous Mat. 7 (2000) 389-392.

56. Yuxiang Qin, Changyu Liu, Mei Liu, Yang Liu, Nanowire (nanorod) arrays-constructed tungsten oxide hierarchical structure and its unique $\mathrm{NO}_{2}$-sensing performances, J. Alloys Comp., 615 (2014) 616-623.

57. C. Zhang, M. Debliguy, A.Boudiba, H. Liao, C. Coddet, Sensing properties of atmospheric plasmasprayed $\mathrm{WO}_{3}$ coating for sub-ppm $\mathrm{NO}_{2}$ detection, Sens. Act. B, 144 (2010) 280-288.

58. S. Dimitrijev, Understanding Semiconductor Devices, Oxford University Press, New York, 2000.

59. S. Karatas, A. Türüt, The determination of Electronic and interface state density distributions of Au/n-type GaAs Schottky barrier diodes, Physica B, 381 (2006) 199-203.

60. M.C.K. Sellers, E. G. Seebauer, Measurement method for carrier concentration in $\mathrm{TiO}_{2}$ via the Mott-Schottky approach, Thin Solid Films, 519 (2011) 2103-2110.

61. W.D. Kingery, H.K. Bowen, D.R. Uhlmann, Introduction in ceramics, John Wiley and Sons, New York, 2000.

62. M. Bhatnagar, B.J. Baliga, H.R. Kirak, G.A. Rozgonyi, Effect of Surface Inhomogeneities on the Electrical Characteristics of SiC Schottky Contacts, IEEE Trans. Electron. Dev., 43 (1996) 150156.

63. Z.L. Weber, R. Gronsky, J. Wasburn, N. Newman, W.E. Spicer, E.R. Weber, Schottky and ohmic Au contacts on GaAs, microscopic and electrical investigation, J. Vac. Sci. Tech. B, 4 (1986) 912918.

64. M. Yagi, S. Maruyama, K. Sone, K. Nagai, T. Norimatsu, Preparation and photoelectrocatalytic activity of a nano-structured $\mathrm{WO}_{3}$ platelet film, J. Solid State Chem. 181 (2008) 175-182.

65. D.N. Gujarathi, G.K. Solanki, M.P. Deshpande, M.K. Agarwal, PEC behaviour of mixed single crystals of tungsten sulphoselenide grown by a CVT technique, Sol. Energy Mater. Sol. Cells, 90 (2006) 2630-2639.

66. M. Okutan, E. Basaran, F. Yakuphanoglu, Electronic and interface state density distribution properties of Ag/p-Si Schottky diode, Appl. Surf. Sci., 252 (2005) 1966-1973.

67. J.P. Sullivan, R.T. Tung, M.R. Pinto, W.R. Graham, Electron transport of inhomogeneous Schottky barriers: A numerical study, J. Appl. Phys., 70 (1991) 7403-7424.

68. L. Andronic, L. Isac, A. Duta, Photochemical synthesis of copper sulphide/titanium oxide photocatalyst, J. Photochem. Photobiol. A, 221 (2011) 30-37.

69. S.F. Matar, G. Campet, Predicting metallic conductivity in oxides from simple chemical criteria, J. Phys. Chem. Solids, 68 (2007) 331-336.

70. M. Grätzel, J.R. Durrant, Dye-sensitised mesoscopic solar cells mary, in: D. Archer, A. J Nozik, Nanostructured and photoelectrochemical systems for solar photon conversion, Imperial College Press, London, 2008, p. 509-512. 


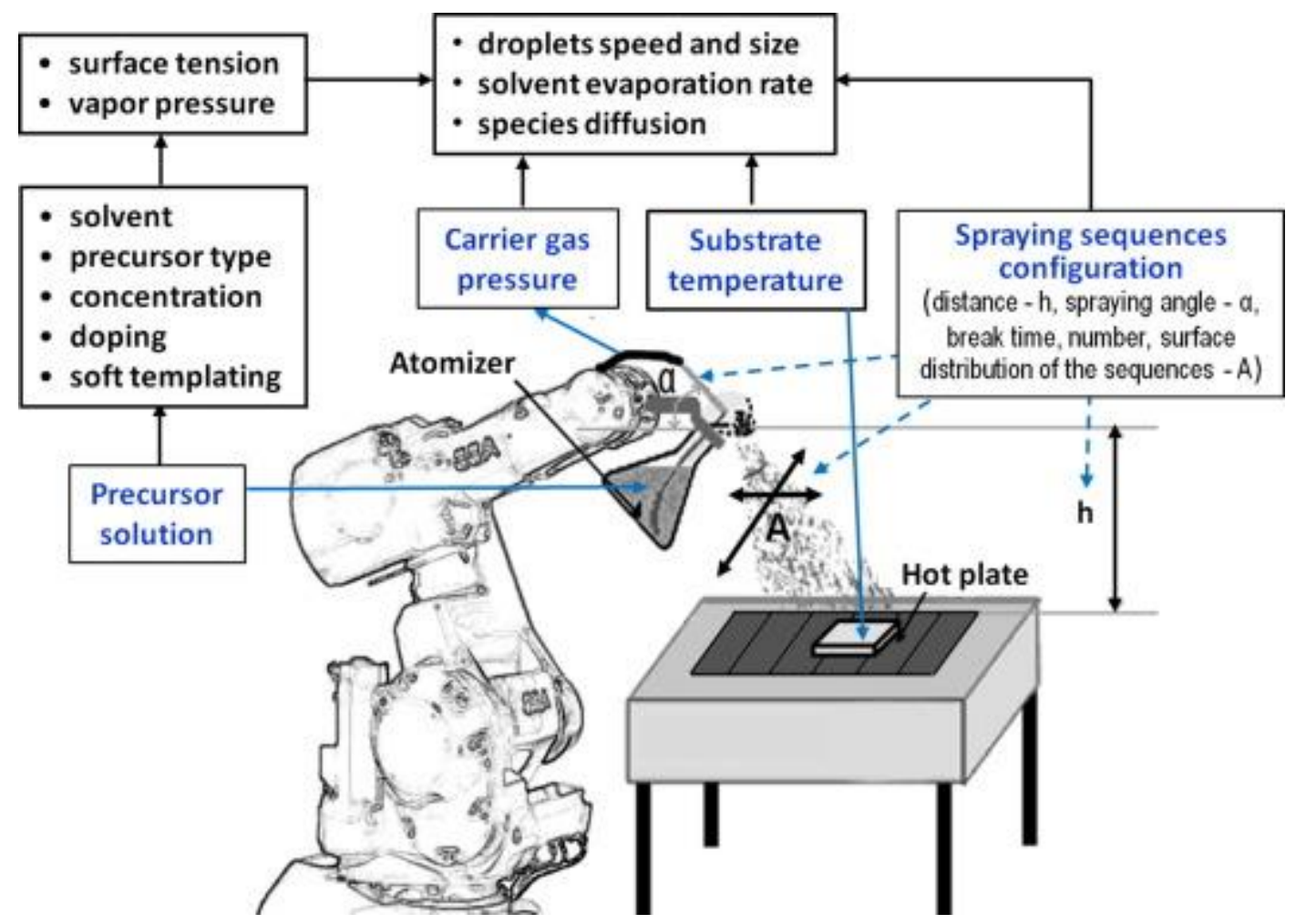

Fig. 1. Comprehensive illustration of the spray pyrolysis process (SPD) showing the variable deposition parameters and their inter-dependency.

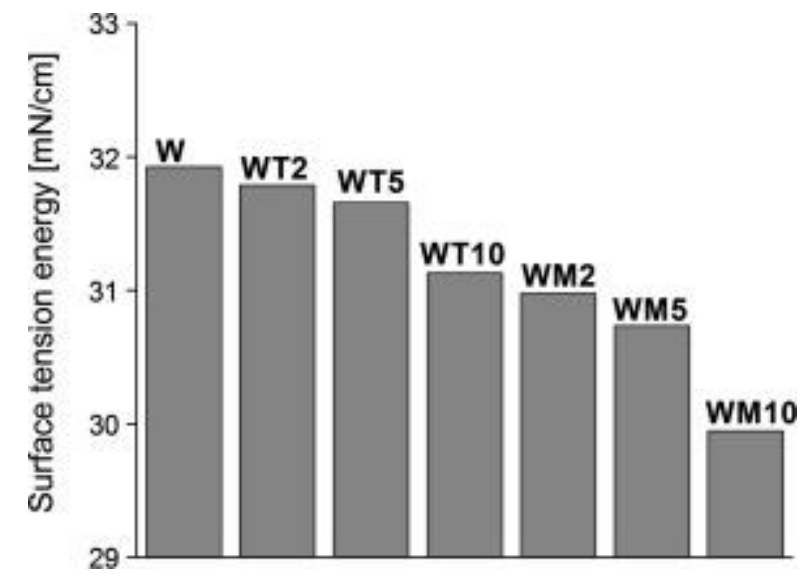

Fig. 2. Surface tension energy values of the spraying solutions with and without additive cation precursors. 

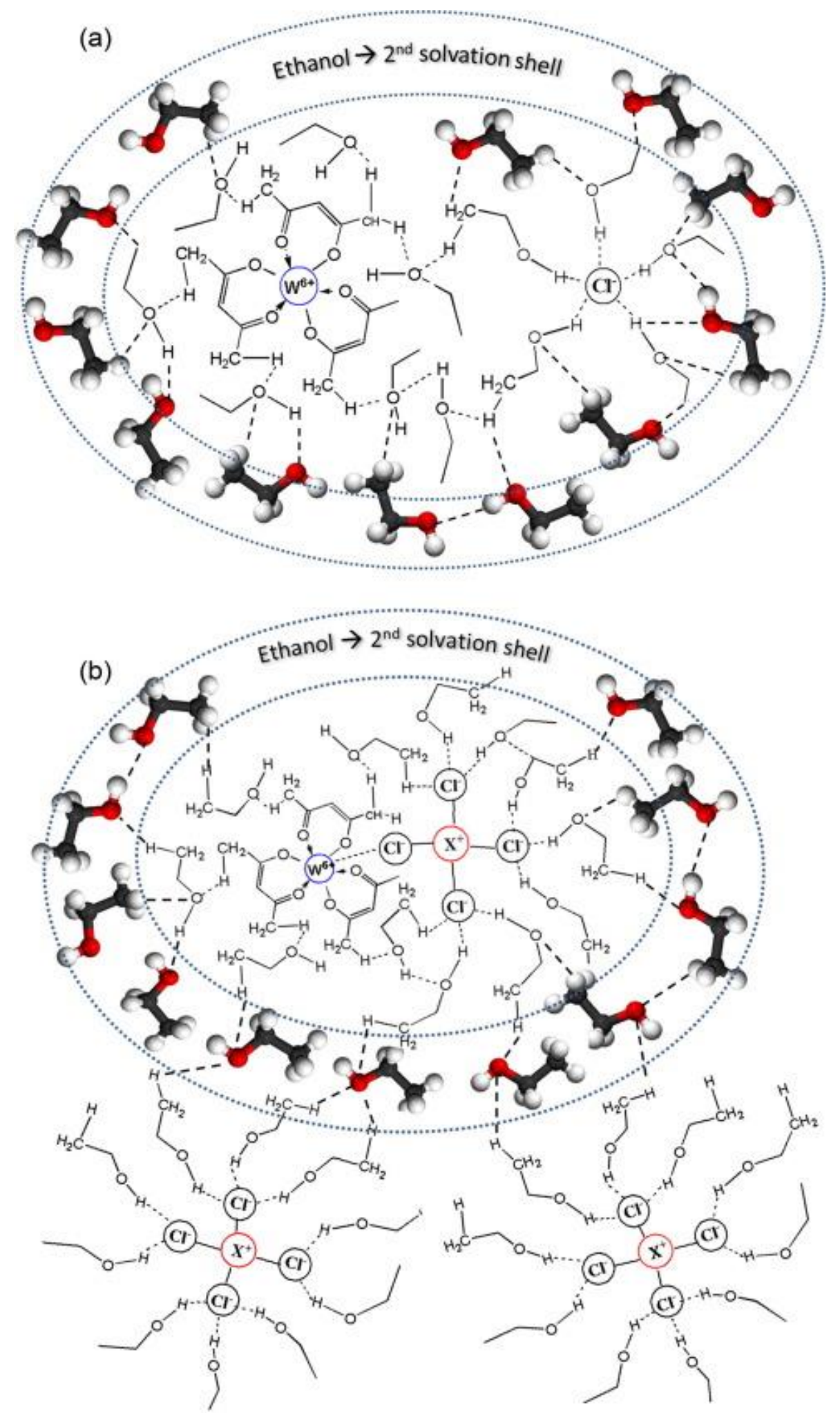

Fig. 3. Illustration of the $\mathrm{W}^{6+}$-AcAc complex solvation in the solution without (a) and in the presence (b) of additives, in the ethanol media. 

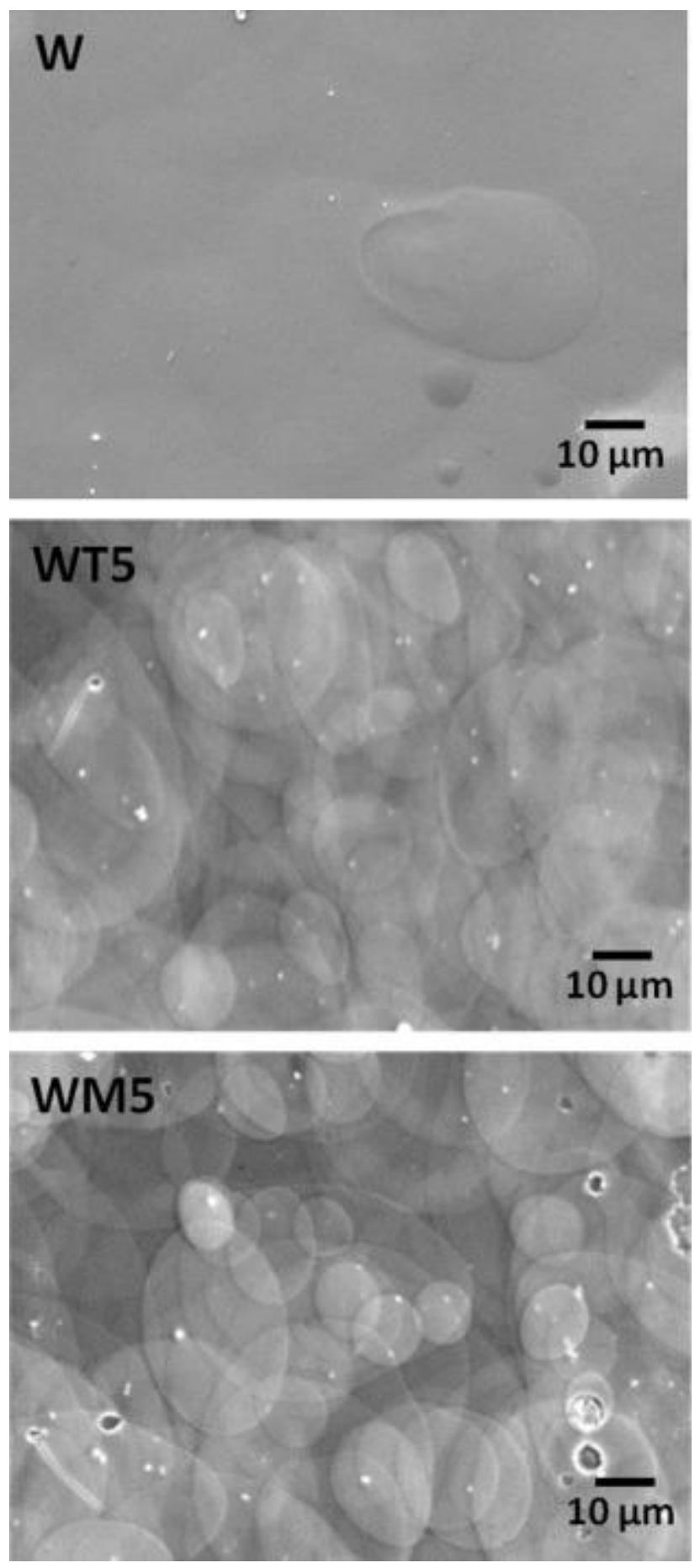

Fig. 4. SEM images of the $\mathrm{WO}_{3}$ film (W) and of the Ti (WT5) and Mo (WM5)-WO $\mathrm{W}_{3}$ films. 

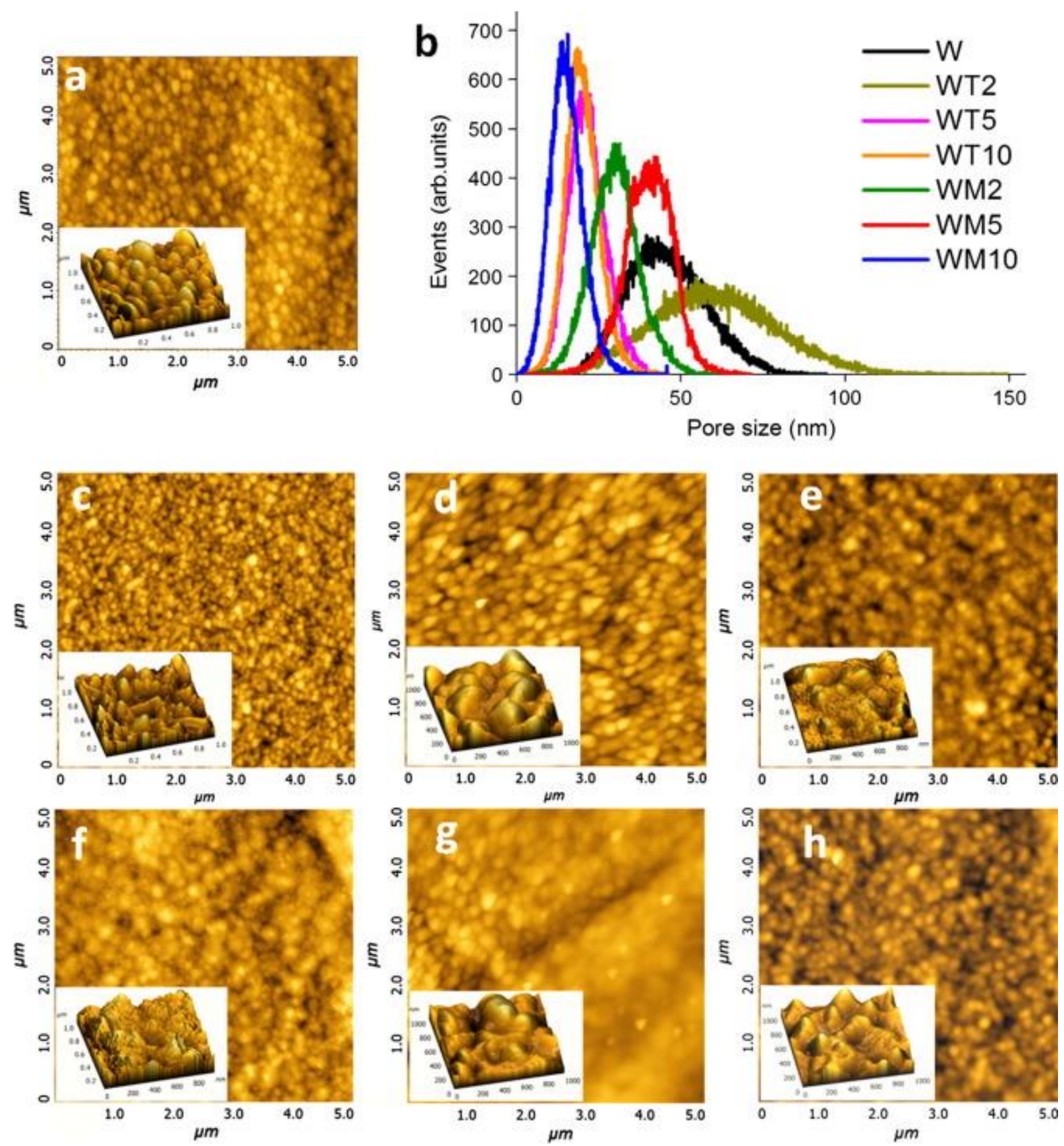

Fig. 5. AFM images of the $\mathrm{WO}_{3}$ film - W(a), Ti - WT2 (c), WT5 (d) and WT10 (e), and Mo - WM2 (f), WM5 (g) and WM10 (h) $\mathrm{WO}_{3}$ films, and pore size distribution (b). 

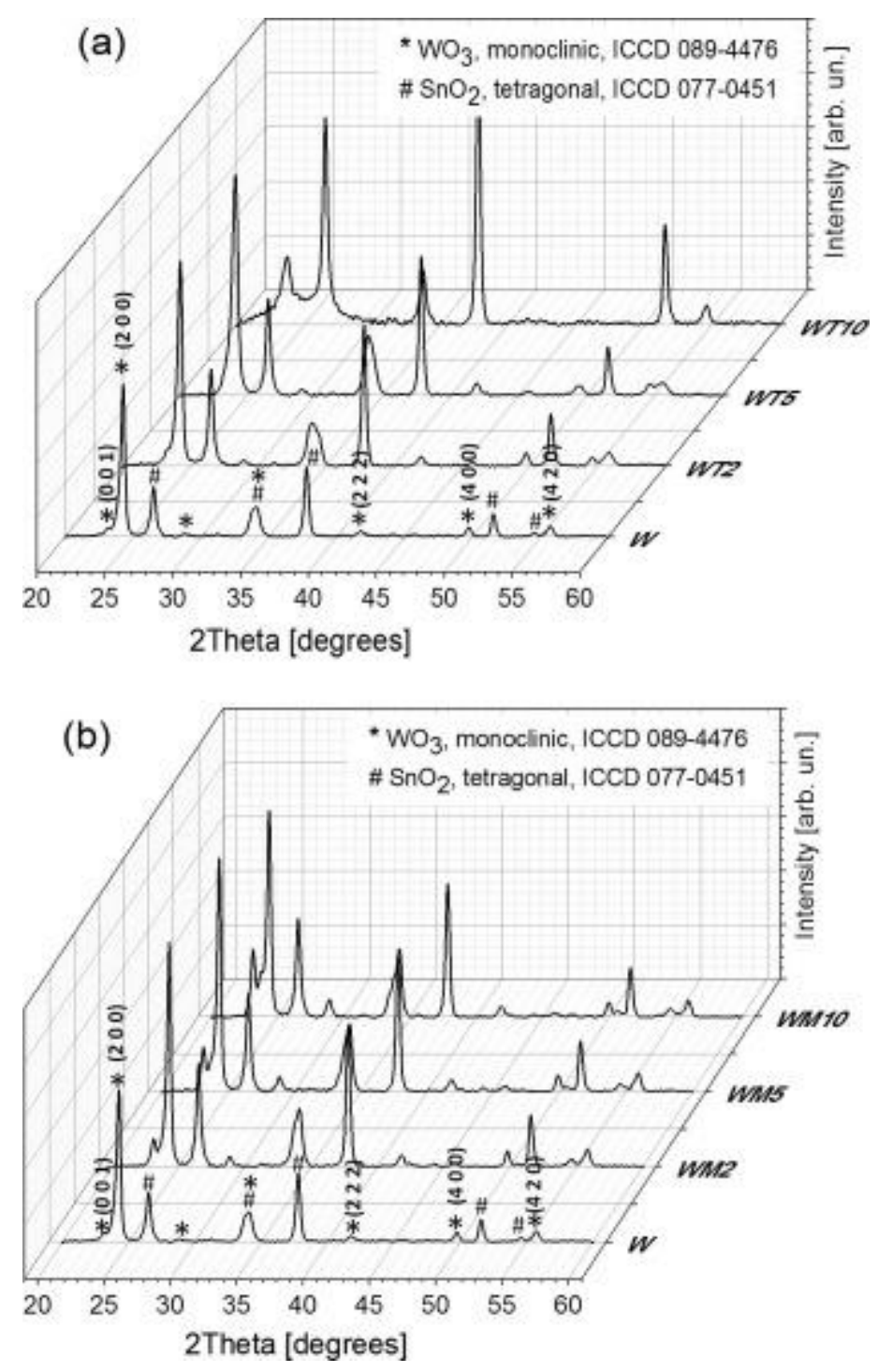

Fig. 6. XRD patterns of the $\mathrm{Ti}-\mathrm{WO}_{3}$ (a) and $\mathrm{Mo}-\mathrm{WO}_{3}$ (b) films presented next to the $\mathrm{WO}_{3}$ film. 

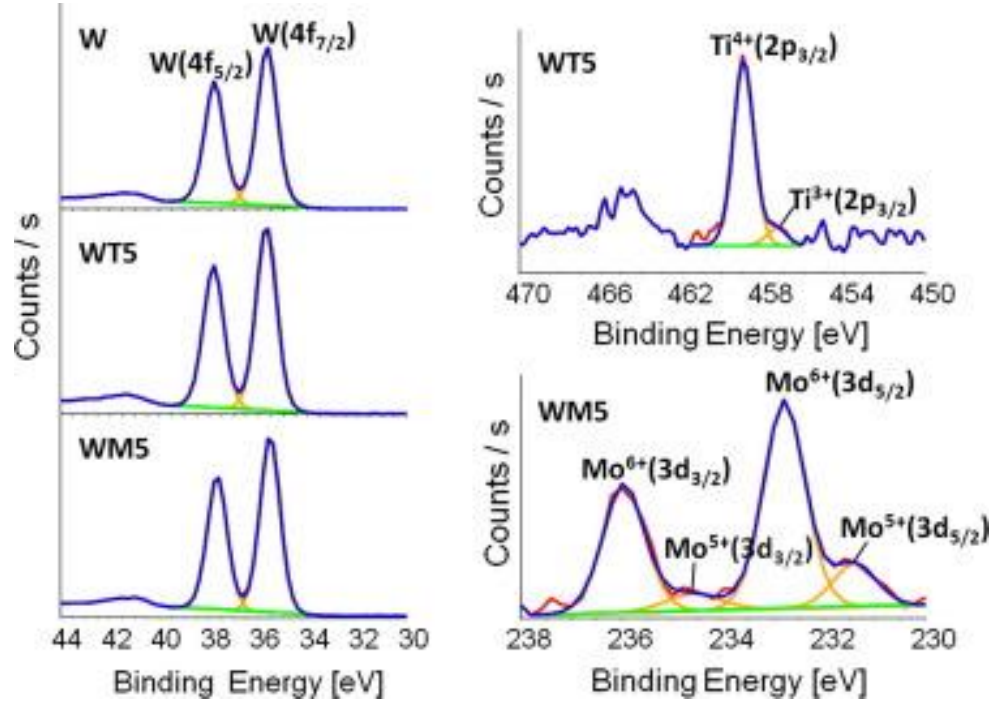

Fig. 7. XPS spectra showing the W4f, Ti2p and Mo3d core levels for the $\mathrm{WO}_{3}(\mathrm{~W})$, and 5 at.\% Ti and $\mathrm{Mo}-\mathrm{WO}_{3}$ films (WT5 and WM5).

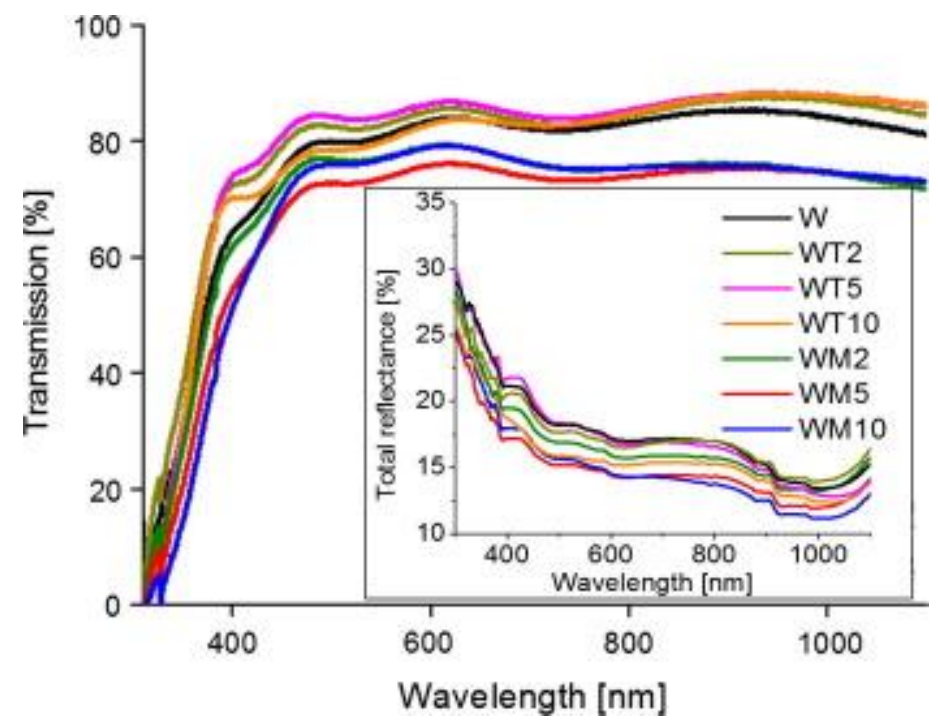

Fig. 8. Transmission spectra (total reflectance spectra in the inset) of the $\mathrm{WO}_{3}$ based layers. Baseline was done with the FTO substrate. 
(a)
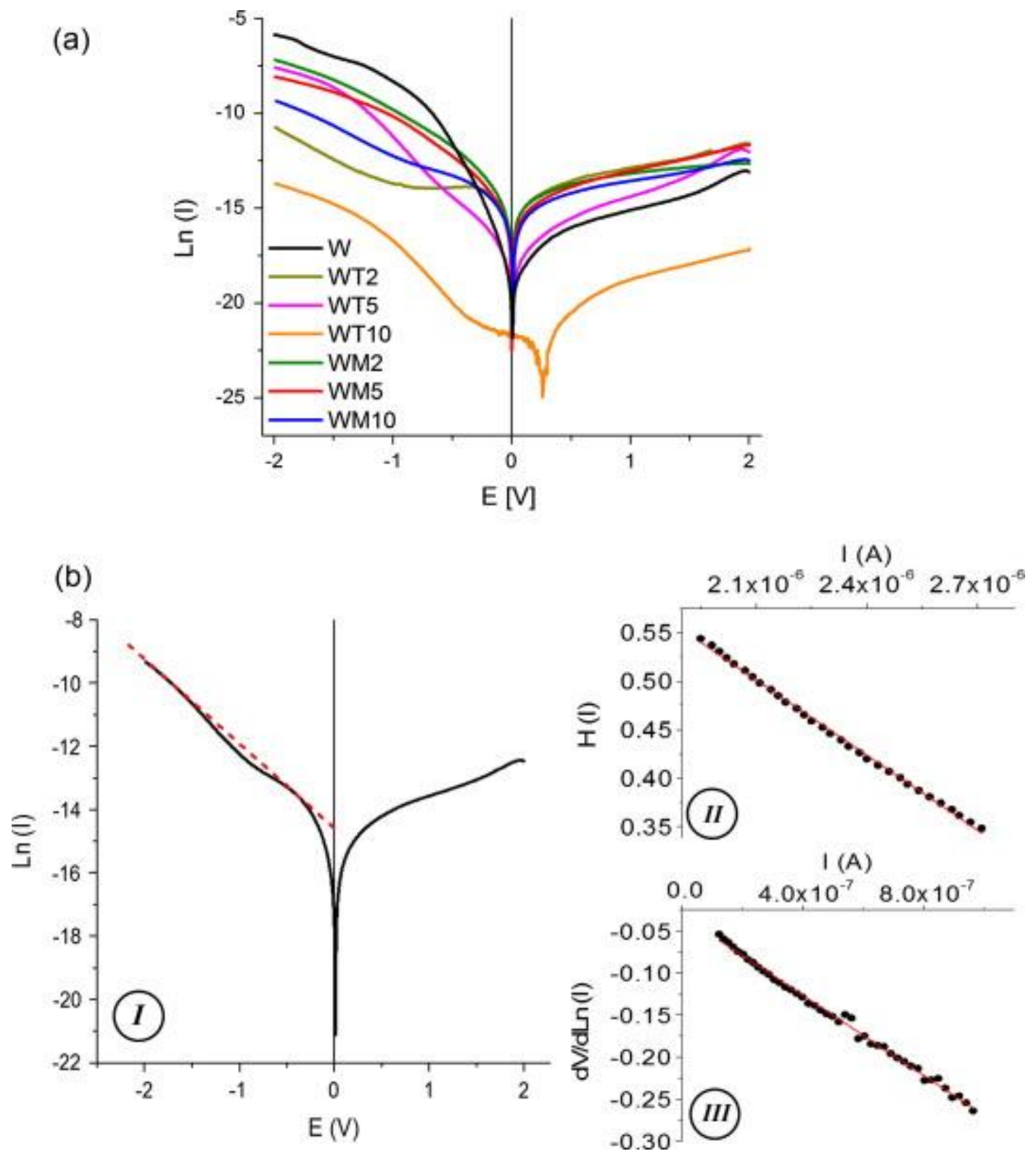

Fig. 9. Representation of the $\mathrm{Ln}(\mathrm{I})$ vs. $\mathrm{V}$ curves for the $\mathrm{WO}_{3}$ based films (a) and examples of reversed saturation current $\left(I_{S}\right)$ extrapolation from the $\operatorname{Ln}(I)$ vs. $E(V)$ curve, $H(I)$ vs. $I(I I)$ and $\mathrm{d} V / \mathrm{d} \ln (I)$ vs. $I(I I I)$ plots for sample WM10 (b). 


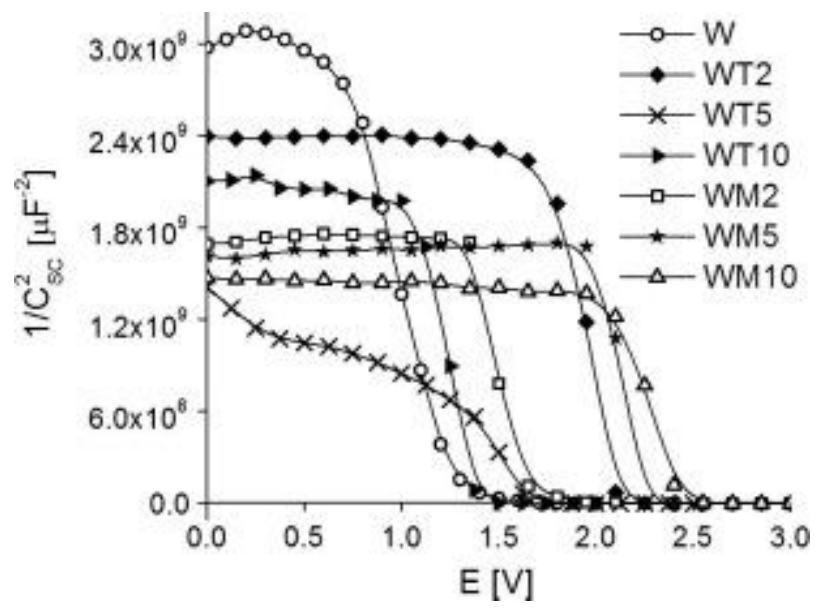

Fig. 10. Mott-Schottky plots of the $\mathrm{WO}_{3}$ based films.

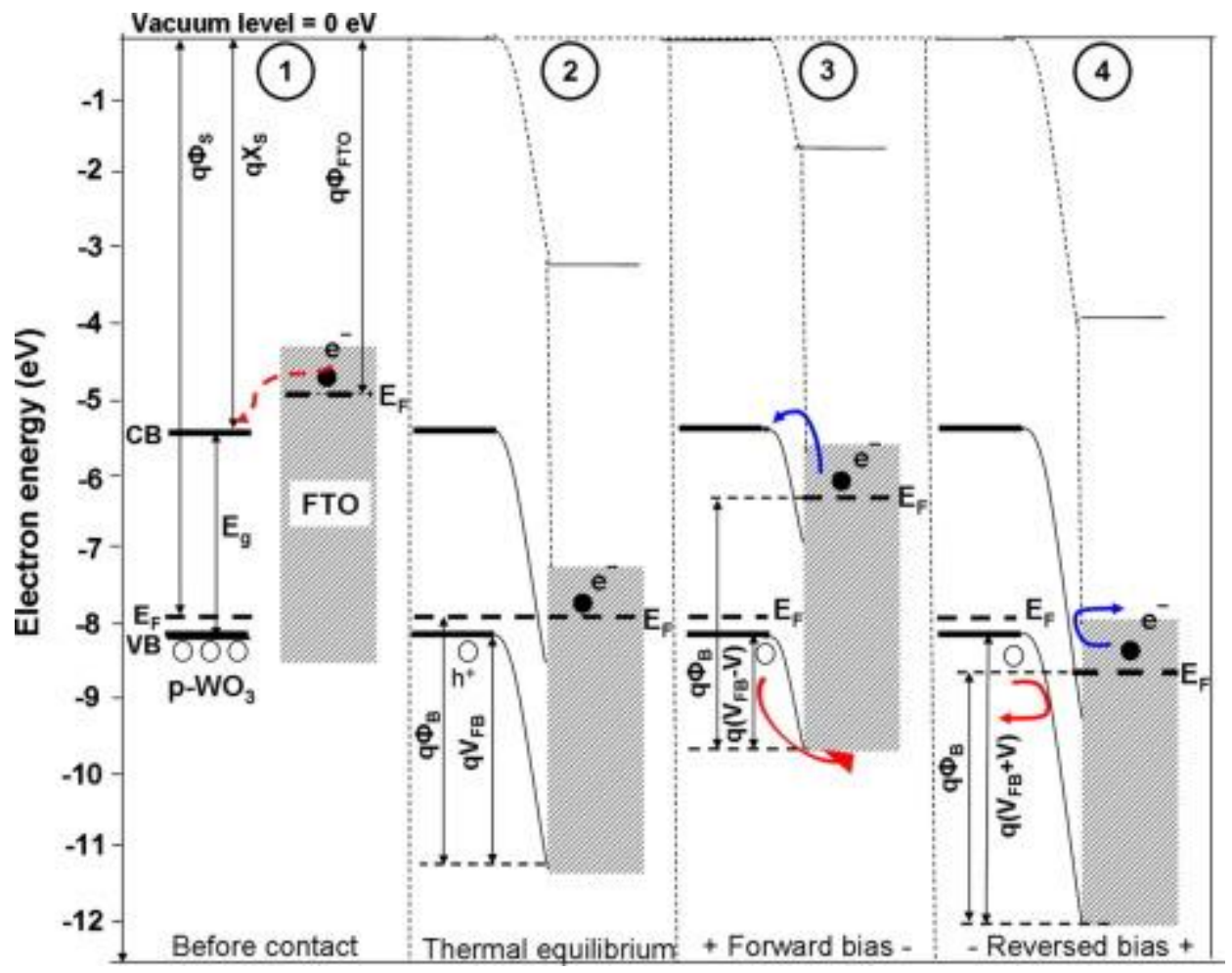

Fig. 11. Band diagram of $\mathrm{FTO} / \mathrm{WO}_{3}$ junction before contact (1), at thermal equilibrium (2), under forward bias (3) and under reversed bias (4). 


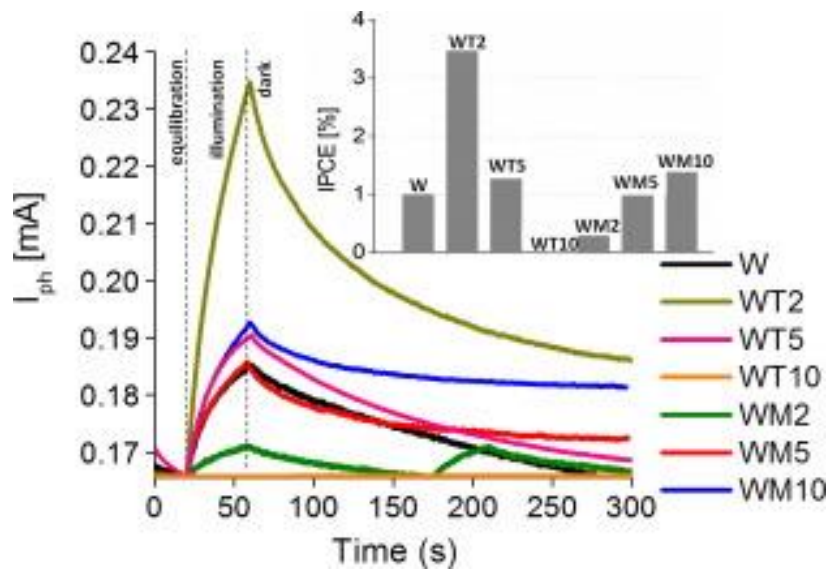

Fig. 12. Photocurrent curves for the $\mathrm{WO}_{3}$ based films with calculated IPCE values (in \%) in the inset. 